\title{
Combating Microbial Contamination with Robust Polymeric Nanofibers: Elemental Effect on the Mussel-Inspired Cross-Linking of Electrospun Gelatin
}

\section{Leung, Chak Ming; Dhand, Chetna; Dwivedi, Neeraj; Xiao, Amy; Ong, Seow Theng; Chalasani, Madhavi Latha Somaraju; Sriram, Harini; Balakrishnan, Yamini; Dolatshahi-Pirouz, Alireza; Orive, Gorka}

Total number of authors:

14

Published in:

ACS Applied Bio Materials

Link to article, DOI:

10.1021/acsabm.8b00666

Publication date:

2019

Document Version

Peer reviewed version

Link back to DTU Orbit

Citation (APA):

Leung, C. M., Dhand, C., Dwivedi, N., Xiao, A., Ong, S. T., Chalasani, M. L. S., Sriram, H., Balakrishnan, Y., Dolatshahi-Pirouz, A., Orive, G., Beuerman, R. W., Ramakkrishna, S., Verma, N. K., \& Lakshminarayanan, R. (2019). Combating Microbial Contamination with Robust Polymeric Nanofibers: Elemental Effect on the MusselInspired Cross-Linking of Electrospun Gelatin. ACS Applied Bio Materials, 2(2), 807-823.

https://doi.org/10.1021/acsabm.8b00666

\section{General rights}

Copyright and moral rights for the publications made accessible in the public portal are retained by the authors and/or other copyright owners and it is a condition of accessing publications that users recognise and abide by the legal requirements associated with these rights.

- Users may download and print one copy of any publication from the public portal for the purpose of private study or research.

- You may not further distribute the material or use it for any profit-making activity or commercial gain

- You may freely distribute the URL identifying the publication in the public portal 


\section{Combating Microbial Contamination with Robust Polymeric Nanofibers: Elemental Effect on the Mussel-inspired Crosslinking of Electrospun Gelatin \\ Chak Ming Leung, Chetna Dhand, Neeraj Dwivedi, Amy Xiao, Seow Theng Ong, Madhavi Latha Somaraju Chalasani, Harini Sriram, Yamini Balakrishnan, Alireza Dolatshahi-Pirouz, Gorka Orive, Roger \\ Wilmer Beuerman, Seeram Ramakrishna, Navin Kumar Verma, and Rajamani Lakshminarayanan} ACS Appl. Bio Mater., Just Accepted Manuscript • DOI: 10.1021/acsabm.8b00666 • Publication Date (Web): 28 Dec 2018 Downloaded from http://pubs.acs.org on December 31, 2018

\section{Just Accepted}

"Just Accepted" manuscripts have been peer-reviewed and accepted for publication. They are posted online prior to technical editing, formatting for publication and author proofing. The American Chemical Society provides "Just Accepted" as a service to the research community to expedite the dissemination of scientific material as soon as possible after acceptance. "Just Accepted" manuscripts appear in full in PDF format accompanied by an HTML abstract. "Just Accepted" manuscripts have been fully peer reviewed, but should not be considered the official version of record. They are citable by the Digital Object Identifier (DOI®). "Just Accepted" is an optional service offered to authors. Therefore, the "Just Accepted" Web site may not include all articles that will be published in the journal. After a manuscript is technically edited and formatted, it will be removed from the "Just Accepted" Web site and published as an ASAP article. Note that technical editing may introduce minor changes to the manuscript text and/or graphics which could affect content, and all legal disclaimers and ethical guidelines that apply to the journal pertain. ACS cannot be held responsible for errors or consequences arising from the use of information contained in these "Just Accepted" manuscripts. 


\section{Combating Microbial Contamination with Robust Polymeric Nanofibers: Elemental Effect on the Mussel-inspired Crosslinking of Electrospun Gelatin}

Chak Ming Leung ${ }^{\mathrm{a}, \uparrow}$, Chetna Dhand ${ }^{\mathrm{b}, \mathrm{c}, \uparrow}$, Neeraj Dwivedi ${ }^{\mathrm{d}, \dagger}$, Amy Xiao ${ }^{\mathrm{e}}$, Seow Theng Ong ${ }^{\mathrm{f}}$, Madhavi Latha Somaraju Chalasani f, Harini Sriram b, Yamini Balakrishnan a, Alireza Dolatshahi-Pirouz $^{\mathrm{g}}$, Gorka Orive ${ }^{\mathrm{h}, \mathrm{i}, \mathrm{j}}$, Roger Wilmer Beuerman ${ }^{\mathrm{b}, \mathrm{c}}$, Seeram Ramakrishna ${ }^{\mathrm{k}}$, Navin Kumar Verma ${ }^{\text {b,f, }}$, Rajamani Lakshminarayanan ${ }^{\text {b,c,*** }}$

a Department of Biomedical Engineering, National University of Singapore, Singapore 117581

b Anti-Infectives Research Group, Singapore Eye Research Institute, The Academia, 20 College Road, Discovery Tower, Singapore 169856

${ }^{c}$ Ophthalmology and Visual Sciences Academic Clinical Program, Duke-NUS Graduate Medical School, Singapore 169857

${ }^{\mathrm{d}}$ Department of Electrical and Computer Engineering, National University of Singapore, 3 Engineering Drive 3, 117583, Singapore

e Department of Biomedical Engineering, Johns Hopkins University, Baltimore, Maryland 21218

${ }^{\mathrm{f}}$ Lee Kong Chian School of Medicine, Nanyang Technological University Singapore, Experimental Medicine Building, 59 Nanyang Drive, Singapore 636921

g Technical University of Denmark, DTU Nanotech, Center for Nanomedicine and Theranostics, 2800 Kgs, Denmark.

${ }^{\mathrm{h}}$ NanoBioCel Group, Laboratory of Pharmaceutics, School of Pharmacy, University of the Basque Country UPV/EHU, Paseo de la Universidad 7, 01006 Vitoria-Gasteiz, Spain.

i Biomedical Research Networking Centre in Bioengineering, Biomaterials, and Nanomedicine (CIBER-BBN). Vitoria-Gasteiz, Spain.

${ }^{\mathrm{j}}$ University Institute for Regenerative Medicine and Oral Implantology - UIRMI, Vitoria, Spain; BTI Biotechnology Institute, Vitoria, Spain.

${ }^{\mathrm{k}}$ Center for Nanofibers and Nanotechnology, Department of Mechanical Engineering, Faculty of Engineering, 2 Engineering Drive 3, National University of Singapore, Singapore 117576

${ }^{\dagger}$ These authors contributed equally to this work.

"Correspondence author: Lee Kong Chian School of Medicine, Nanyang Technological University Singapore, Experimental Medicine Building, 59 Nanyang Drive, Singapore 636921

** Correspondence author: Anti-Infectives Research Group, Singapore Eye Research Institute, The Academia, 20 College Road, Discovery Tower, 169856, Singapore

E-mail address: lakshminarayanan.rajamani@seri.com.sg (R. Lakshminarayanan), nkverma@ntu.edu.sg (N.K. Verma). 


\begin{abstract}
Designing biocompatible nanofibrous mats capable of preventing microbial colonization from resident and nosocomial bacteria for an extended period remains an unmet clinical need. In the present work, we designed antibiotic free durable antimicrobial nanofiber mats by taking advantage of synergistic interactions between polydopamine (pDA) and metal ions with varying degree of antimicrobial properties $\left(\mathrm{Ag}^{+}, \mathrm{Mg}^{2+}, \mathrm{Ca}^{2+}\right.$ and $\left.\mathrm{Zn}^{2+}\right)$. Microscopic analysis showed successful pDA-mediated crosslinking of the gelatin nanofibers which further improves by the inclusion of $\mathrm{Ag}^{+}, \mathrm{Mg}^{2+}$ and $\mathrm{Ca}^{2+}$ ions as supported by mechanical and thermal studies. Spectroscopic results reinforce the presence of strong interactions between pDA and metal ions in the composite nanofibers, leading to generation of robust polymeric nanofibers. We further showed that strong pDA-Ag interactions attenuated the cell cytotoxicity and anti-cell proliferative properties of silver ions for immortalized keratinocytes and primary human dermal fibroblasts. pDA-/Ca ${ }^{2+} / \mathrm{Zn}^{2+}$ interactions rendered the composite structure sterile against methicillin-resistant Staphylococcus aureus and vancomycin-resistant Enterococcus faecium strains whereas the silver ion-incorporated composite mats displayed broad spectrum antibacterial activity against both Gram-positive/-negative bacteria and yeast strains. We showed that the strong pDA-Ag interactions help retaining long-term antimicrobial activity of the mats for at least 40 days while attenuating mammalian cell cytotoxicity of silver ions for skin cells. Overall, the results suggest the potential of pDAmetal ion interactions for engineering sterile nanofibrous mats and expanding the antibiotic armamentarium against drug-resistant pathogens.
\end{abstract}

Keywords: Antimicrobial, Polydopamine Crosslinking, Electrospinning, Gelatin, Metal Ions, Tissue engineering 


\section{Introduction}

Decades of overuse and misuse of antibiotics has resulted in the evolution of antibiotic resistant bacterial strains. Every year in the United States, at least 2 million people become infected with antibiotic resistant bacterial strains, and approximately 23,000 people die annually due to failure in combating such resistant strains. ${ }^{1}$ This highlights the need to discover new generation antimicrobial agents that can promote broad spectrum antimicrobial activity against antibiotic resistant strains. In the era of increasing evolution of antibiotic resistant pathogens, alternative strategies are needed to combat microbial colonization in both healthcare and industrial settings. ${ }^{2,3}$ A growing interest in the use of metal ions as antimicrobials has surfaced to augment the ongoing battle against antibiotic resistant bacterial strains. Silver is one of the most common examples of antimicrobial metal ions, and had been used extensively until the beginning of the antibiotics era. ${ }^{4}$ Alkaline earth and transition metal ions also possess antimicrobial activity against Gram-positive and Gram-negative planktonic bacteria, though higher concentrations are required to achieve similar effects when compared to silver or mercury ions. ${ }^{5-7}$

Metals/metal ions with inherent antimicrobial properties have been used in a number of healthcare and personal care products. For example, silver wound dressings Acticoat ${ }^{\mathrm{TM}}$ have shown $99 \%$ reduction in bacterial viability including Methicillin-resistant Staphylococcus aureus (MRSA), P. aeruginosa, Vancomycin-resistant Enterococci (VRE), and Candida albicans. ${ }^{8} \mathrm{Ag}$ alloy and hydrogel coated catheters have benefited the patients by reducing the incidences of nosocomial urinary tract infections. ${ }^{9}$ Biocompatible coating designed using the combination $\mathrm{Ag}$ and $\mathrm{Ti}$ have demonstrated antimicrobial effectiveness against S. aureus and Klebsiella pneumonia. ${ }^{10} \mathrm{Cu}$-based coatings have shown antimicrobial activity against Escherichia coli, including a verocytotoxigenic E. coli, Listeria monocytogenesnm, Salmonella enterica, Camplylobacter jejuni, Mycobacterium tuberculosis, 
vancomycin-resistant Enterococci, methicillin-resistant $S$. aureus. ${ }^{11-16}$ Moreover, the $\mathrm{Cu} / \mathrm{Ag}$ ionizers are commonly used to control Legionella in drinking water systems in hospitals to prevent nosocomial infections. ${ }^{17}$ However, one of the critical factors that limit their enhanced therapeutic utility is the metal ion induced cytotoxicity at higher concentrations which can cause adverse tissue reactions including accumulation in organs, allergy, carcinoma etc. Hence, this drawback, possibly due to limited understanding of metal ion-polymer systems, constitutes a major barrier for exploration of metals/metal ions and their integration in designing anti-infective materials. Therefore, the proposal of novel schemes to overcome metal-ions induced concerns, exploration of novel metal ions and greater insight into the metal- ion-polymer systems are of central interest for designing next generation advanced anti-infective materials.

Electrospinning is a cost-effective method available for producing nanofibrous mats with high surface areas, porosities, good mechanical strength and a morphology that imitates the dimensions of extra-cellular matrix. ${ }^{18,19}$ These morphological and structural features help to enhance haemostasis, fluid absorption, gas permeation and cell proliferation, which makes nanofibrous mats ideal candidates for biomedical applications. ${ }^{20}$ Numerous reports are available pertaining to antibiotics-laden electrospun nanofibers to generate wound dressings with antimicrobial potential. For example, the fabrication of electrospun polycaprolactone (PCL) mats containing rifampicin and polyvinyl Alcohol (PVA) mats containing gentamicin has been reported. ${ }^{21,22}$ While these studies demonstrate successful incorporation of antibiotics inside electrospun nanofibers and confirm their antimicrobial activity, concerns on the development of resistant strains persist as the effective drug concentration depletes in the biological milieu with duration of treatment. Therefore, sustained release of an effective dose of antimicrobials for an extended period of time is desirable in averting microbial colonization and limiting the evolution of antimicrobial resistance. In our previous work, we 
have developed durable antimicrobial wound dressings taking advantage of the strong interfacial interactions between polyhydroxy antibiotics and gelatin and their in-situ crosslinking with polydopamine using ammonium carbonate diffusion method (ADM). ${ }^{23}$ Polydopamine crosslinking resulted in sustained release of the antibiotics containing $\geq 5-\mathrm{OH}$ groups with complete retention of antimicrobial activity for more than 20 days. Furthermore, the antibiotic loaded mats promoted wound healing in a porcine model of partial thickness burns when compared to mats without antibiotics. ${ }^{23}$

Taking advantage of the strong chelating ability of catechol groups in polydopamine (pDA) for metal ions, we design robust polymeric (gelatin) nanofibers via synergistic effect of metal ions ( $\mathrm{Mg}, \mathrm{Zn} \mathrm{Ca}$ and $\mathrm{Ag}$ ) and pDA chemistry which promotes nanofibers crosslinking. We comprehensively characterized the newly developed mineralized composite materials for structural, bonding, morphological, thermal and mechanical properties. The analysis unravels many critical aspects of metal ions-polymer interaction and reveals the robustness of resultant materials. Interestingly, pDA-mineralized composite structures, produced by our facile strategy (Scheme 1), demonstrated excellent long-term anti-microbial activities and good biocompatibility for skin cells. 
Scheme 1. Schematic illustration of A) Fabrication of polydopamine crosslinked metal ion $\left(\mathrm{M}^{\mathrm{n}+}\right)$ loaded gelatin mats using electrospinning technique followed by post-spinning ammonium carbonate diffusion. B) Interactions involved in the formation of stable Gel_pDA_M ${ }^{\mathrm{n}+}$ architecture for controlled release of the metal ions.

\section{MATERIALS AND METHODS}

2.1. Materials and Reagents. Gelatin (Gel, Type A from porcine skin), dopamine hydrochloride (DA), silver nitrate $\left(\mathrm{AgNO}_{3}\right)$, Anhydrous calcium chloride $\left(\mathrm{CaCl}_{2}\right)$, Anhydrous magnesium chloride $\left(\mathrm{MgCl}_{2}\right)$, zinc chloride $\left(\mathrm{ZnCl}_{2}\right)$, 2,2,2-trifluoroethanol (TFE), FITCconjugated anti- $\alpha$-tubulin, Fluoromount ${ }^{\mathrm{TM}}$, Hoechst and ammonium carbonate were procured from Sigma-Aldrich (Singapore). Mueller-Hinton agar (MHA) and Sabouraud's Dextrose Agar (SDA) were purchased from Acumedia, Neogen Corporation, Michigan, USA. Dulbecco's Modified Eagle's Medium (DMEM) growth medium was from Gibco®. All other cell culture reagents were obtained from Life Technologies Thermo Fisher Scientific, Singapore. 
2.2. Bacterial Strains used in the present study: Table 1 shows the various microbial strains have been used for the antimicrobial assessment of different mats.

Table 1. Various microbial strains used to evaluate the antimicrobial potential of various nanofibrous mats.

\begin{tabular}{|c|c|c|}
\hline $\begin{array}{c}\text { Gram positive bacterial } \\
\text { strains }\end{array}$ & $\begin{array}{c}\text { Gram negative bacterial } \\
\text { strains }\end{array}$ & Yeast Strains \\
\hline MRSA 9808R (from eye) & PA 9027 (ATCC) & CA 10231 (ATCC) \\
\hline MRSA 700699 (ATCC) & PA 01 (ATCC) & CA DF0001976R \\
\hline B. subtilis 6633 (ATCC) & KP 10031 (ATCC) & colon) \\
\hline B. cereus 11778 (ATCC) & KP DM4299 (from eye) & \\
\hline VRE 1001 & 606 (ATCC) & \\
\hline VRE 1002 & AB 1001 & \\
\hline \multicolumn{3}{|c|}{$\begin{array}{l}\text { Abbreviations Used in the Table: MRSA, Methicillin-resistant } S \text {. aureus; VRE, Vancomycin- } \\
\text { resistant Enterococci; PA, Pseudomonas aeruginosa; KP, Klebsiella pneumoniae; AB, Acinetobacter } \\
\text { baumanni; CA, Candida albicans. }\end{array}$} \\
\hline
\end{tabular}

\subsection{Electrospinning of Metal and Dopamine Incorporated Gelatin Mats. For} electrospinning of gelatin nanofibers, $10 \%(\mathrm{w} / \mathrm{v})$ gelatin solution was prepared in TFE and kept for overnight stirring to homogenize. The composition of the dope solution employed to prepare dopamine and metal ions integrated gelatin mats is compiled as Table $\mathbf{2}$ and images for all the solutions are shown in Figure S1. In the electrospinning unit, the dope solution was fed into the standard polypropylene syringe connected to a $27 \mathrm{G}$ (Braun, internal diameter $0.4 \mathrm{~mm}$ ) stainless steel nozzle and mounted on a syringe pump (KDS-100, kD Scientific, USA). The nanofibers were collected on the aluminum foil wrapped collector plate, which was placed at the distance (SD) of $12-15 \mathrm{~cm}$ from the syringe tip by applying high voltage (Gamma High Voltage Research, Inc., FL, USA) in the range of 7-14 KV at 0.5$1.0 \mathrm{~mL} / \mathrm{h}$ feed rate. The optimized electrospinning parameters for the preparation of various nanofiber mats with the assigned sample codes are given in Table 2. All electrospinning experiments were performed at $25{ }^{\circ} \mathrm{C}$ in air. The nanofibrous mats were dried in a vacuum desiccator for $72 \mathrm{~h}$ to remove any residual solvent and later stored in a dry cabinet for future experiments. 
Table 2. Electrospinning details and parameters for various gelatin mats prepared in the present study and their acronyms used.

\begin{tabular}{|c|c|c|c|}
\hline $\begin{array}{c}\text { Sample } \\
\text { Abbreviation }\end{array}$ & Details & $\begin{array}{c}\text { Dope Solution } \\
\text { Composition }\end{array}$ & $\begin{array}{c}\text { Electrospinning } \\
\text { Parameters }\end{array}$ \\
\hline ES_Gel & $\begin{array}{l}\text { Pristine gelatin (Gel) } \\
\text { mats }\end{array}$ & $\begin{array}{l}10 \% \text { Gelatin (w/v, in } \\
\text { TFE) }\end{array}$ & $\begin{array}{l}\text { Voltage }=11.5 \mathrm{kV} \\
\mathrm{SD}=12 \mathrm{~cm} \\
\text { Flow Rate }=1 \mathrm{~mL} / \mathrm{h}\end{array}$ \\
\hline Gel_DA & $\begin{array}{l}\text { Dopamine }(\mathrm{DA}) \\
\text { incorporated gelatin } \\
\text { mats }\end{array}$ & $\begin{array}{l}10 \% \text { Gelatin }+2 \% \text { DA } \\
(w / w \text { of gelatin) in TFE }\end{array}$ & $\begin{array}{l}\text { Voltage }=11.5 \mathrm{kV} \\
\mathrm{SD}=12 \mathrm{~cm} \\
\text { Flow Rate }=1 \mathrm{~mL} / \mathrm{h}\end{array}$ \\
\hline Gel_Ag & $\begin{array}{l}\text { Silver }\left(\mathrm{Ag}^{+}\right) \\
\text {incorporated gelatin } \\
\text { mats }\end{array}$ & $\begin{array}{l}10 \% \text { Gelatin }+1.2 \% \\
\mathrm{Ag}^{+}(\text {w/w of gelatin }) \text { in } \\
90 \% \text { TFE }\end{array}$ & $\begin{array}{l}\text { Voltage }=11.5 \mathrm{kV} \\
\mathrm{SD}=12 \mathrm{~cm} \\
\text { Flow Rate }=0.8 \mathrm{~mL} / \mathrm{h}\end{array}$ \\
\hline Gel_Mg & $\begin{array}{l}\text { Magnesium }\left(\mathrm{Mg}^{2+}\right) \\
\text { incorporated gelatin } \\
\text { mats }\end{array}$ & $\begin{array}{l}10 \% \text { Gelatin }+1.2 \% \\
\mathrm{Mg}^{2+}(\mathrm{w} / \mathrm{w} \text { of gelatin) in } \\
90 \% \mathrm{TFE}\end{array}$ & $\begin{array}{l}\text { Voltage }=14.0 \mathrm{kV} \\
\mathrm{SD}=15 \mathrm{~cm} \\
\text { Flow Rate }=1 \mathrm{~mL} / \mathrm{h}\end{array}$ \\
\hline Gel_Ca & $\begin{array}{l}\text { Calcium }\left(\mathrm{Ca}^{2+}\right) \\
\text { incorporated gelatin } \\
\text { mats }\end{array}$ & $\begin{array}{l}10 \% \text { Gelatin }+1.2 \% \\
\mathrm{Ca}^{2+}(\text { w/w of gelatin }) \text { in } \\
90 \% \text { TFE }\end{array}$ & $\begin{array}{l}\text { Voltage }=11.5 \mathrm{kV} \\
\mathrm{SD}=12 \mathrm{~cm} \\
\text { Flow Rate }=0.8 \mathrm{~mL} / \mathrm{h}\end{array}$ \\
\hline Gel_Zn & $\begin{array}{l}\text { Zinc }\left(\mathrm{Zn}^{2+}\right) \text { incorporated } \\
\text { gelatin mats }\end{array}$ & $\begin{array}{l}10 \% \text { Gelatin }+1.2 \% \\
\mathrm{Zn}^{2+} \text { (w/w of gelatin) in } \\
90 \% \mathrm{TFE}\end{array}$ & $\begin{array}{l}\text { Voltage }=7.0 \mathrm{kV} \\
\mathrm{SD}=14 \mathrm{~cm} \\
\text { Flow Rate }=0.5 \mathrm{~mL} / \mathrm{h}\end{array}$ \\
\hline Gel_DA_Ag & $\begin{array}{l}\text { Silver }\left(\mathrm{Ag}^{+}\right) \text {and } \\
\text { Dopamine incorporated } \\
\text { gelatin mats }\end{array}$ & $\begin{array}{l}10 \% \text { Gelatin }+2 \% \mathrm{DA}+ \\
1.2 \% \mathrm{Ag}^{+} \text {in } 90 \% \mathrm{TFE}\end{array}$ & $\begin{array}{l}\text { Voltage }=11.5 \mathrm{kV} \\
\mathrm{SD}=12 \mathrm{~cm} \\
\text { Flow Rate }=0.8 \mathrm{~mL} / \mathrm{h}\end{array}$ \\
\hline Gel_DA_Mg & $\begin{array}{l}\text { Magnesium }\left(\mathrm{Mg}^{2+}\right) \text { and } \\
\text { Dopamine incorporated } \\
\text { gelatin mats }\end{array}$ & $\begin{array}{l}10 \% \text { Gelatin }+2 \% \mathrm{DA}+ \\
1.2 \% \mathrm{Mg}^{2+} \text { in } 90 \% \mathrm{TFE}\end{array}$ & $\begin{array}{l}\text { Voltage }=14.0 \mathrm{kV} \\
\mathrm{SD}=15 \mathrm{~cm} \\
\text { Flow Rate }=1 \mathrm{~mL} / \mathrm{h}\end{array}$ \\
\hline Gel_DA_Ca & $\begin{array}{l}\text { Calcium }\left(\mathrm{Ca}^{2+}\right) \text { and } \\
\text { Dopamine incorporated } \\
\text { gelatin mats }\end{array}$ & $\begin{array}{l}10 \% \text { Gelatin }+2 \% \mathrm{DA}+ \\
1.2 \% \mathrm{Ca}^{2+} \text { in } 90 \% \text { TFE }\end{array}$ & $\begin{array}{l}\text { Voltage }=11.5 \mathrm{kV} \\
\mathrm{SD}=12 \mathrm{~cm} \\
\text { Flow Rate }=0.8 \mathrm{~mL} / \mathrm{h}\end{array}$ \\
\hline Gel_DA_Zn & $\begin{array}{l}\text { Zinc }\left(\mathrm{Zn}^{2+}\right) \text { and } \\
\text { Dopamine incorporated } \\
\text { gelatin mats }\end{array}$ & $\begin{array}{l}10 \% \text { Gelatin }+2 \% \mathrm{DA}+ \\
1.2 \% \mathrm{Zn}^{2+} \text { in } 90 \% \text { TFE }\end{array}$ & $\begin{array}{l}\text { Voltage }=10.5 \mathrm{kV} \\
\mathrm{SD}=14.5 \mathrm{~cm} \\
\text { Flow Rate }=0.6 \mathrm{~mL} / \mathrm{h}\end{array}$ \\
\hline
\end{tabular}

\subsection{Ammonium Carbonate Mediated Crosslinking for Dopamine Incorporated Gelatin}

Mats. To accomplish polydopamine (pDA) crosslinking and metal carbonate structuring in dopamine incorporated mats, the mats were kept in a sealed desiccator containing ammonium carbonate powder in a petri plate for $24 \mathrm{~h}$, which we designate as the ammonium carbonate diffusion method (ADM). Thus, prepared crosslinked mats were then vacuum dried for $24 \mathrm{~h}$ 
and used for further studies. The crosslinked mats are named as Gel_pDA, Gel_pDA_Ag, Gel_pDA_Mg, Gel_pDA_Ca and Gel_pDA_Zn for better clarity.

2.5. Mechanical Properties of the Nanofiber Mats. Tensile properties of the mats were determined using table top tensile testing machine (Instron 5345, USA) following the ASTMD882-02 protocol standard. Each fiber mat was cut into $1 \mathrm{~cm} \times 3 \mathrm{~cm}$ rectangular shape strips and the thickness of the samples was determined by a digital micrometre. Stress-strain curves were documented employing the cross-section speed of $1 \mathrm{~mm} \min ^{-1}$. Mechanical properties (tensile strength, Young's Modulus, failure strain and work of failure) of different mats were then estimated using the recorded stress-strain curves. At least three samples were tested for each sample type and the average values were recorded.

\subsection{Morphological Analysis using Field-Emission Scanning Electron Microscopy (FE-} SEM) \& Transmission Electron Microscopy (TEM). Morphology of different nanofiber mats were examined using field-emission scanning electron microscope (FE-SEM; JEOL JSM6701F, the Netherlands) and transmission electron microscope (TEM; JEOL JEM-3010). For FE-SEM analysis, the samples were first sputter coated with platinum (JEOL JSC-1200 fine coater, Japan) and viewed at an accelerating voltage of $5 \mathrm{kV}$. To estimate the average fiber diameter of various nanofibrous mats, $\sim 50$ distinct individual fibers from different areas were randomly selected and used for measuring their diameter using Image $\mathbf{J}$ software. In the TEM study, the fibers were collected on gold-coated copper specimen grids without staining.

2.7. Dynamic Contact Angle Analysis. To investigate the surface wettability of the mats, we monitored the time-dependent deviations in the water contact angle on various electrospun mats using VCA Optima Surface Analysis System (AST products, MA, USA). For this, $1 \mu \mathrm{L}$ of MilliQ water was dropped onto the fiber mats collected on glass cover slips and 
photographed continuously at different time intervals including $0,5,10,20,30,40,50,60,90$ \&120 s. The average values were reported from two independent experiments.

2.8. X-Ray Photoelectron Spectroscopy. XPS studies were executed in a Kratos AXIS UltraVLD (Kratos Analytical Ltd) system using base pressure of $\sim 10^{-9}$ Torr. Photoemission was induced by $\mathrm{Al} \mathrm{K \alpha}(1486.71 \mathrm{eV})$ radiation using physical electronics $04-548$ dual $\mathrm{Mg} / \mathrm{Al}$ anode. XPSPEAK 4.1 is used to curve resolve the XPS data after subtracting the Shirley background. The curve resolved spectra were fit with the minimum number of peaks which were needed to reproduce the spectral features with a 75\% Gaussian/ 25\% Lorentzian peak shape using a Gaussian-Lorentzian product function.

2.9. Thermogravimetric Analysis. The Q500 thermal analyzer (TA Instruments, DE, USA) was used to perform the thermogravimetric analysis (TGA) of GEL, metal incorporated gelatin mats and all the dopamine incorporated metal loaded gelatin mats at a heating rate of $20{ }^{\circ} \mathrm{C} / \mathrm{min}$ from $25-900{ }^{\circ} \mathrm{C}$ in a dynamic nitrogen atmosphere having a flow rate of 60 $\mathrm{mL} / \mathrm{min}$.

2.10. Radial disc diffusion assay. The antimicrobial properties of various metal loaded pDA crosslinked mats were assessed using Kirby-Bauer radial disc diffusion method in accordance with Clinical and Laboratory Standards Institute (CLSI). For this, Gram positive and Gram negative bacterial cultures (at a concentration of $0.5 \mathrm{McF}$ arland standards) were spread onto the surface of sterile Muller Hinton agar (MHA) plates using a cotton swab in 9 $\mathrm{cm}$ diameter Petri dishes. To evaluate their antifungal efficiency, yeast cultures (at a concentration of 0.5 McFarland standards) were spread onto the surface of sterile SDA plates. Various metal loaded mats (Gel_pDA_Ag, Gel_pDA_Mg, Gel_pDA_Zn and Gel_pDA_Ca) were placed in the dimension of $1 \mathrm{~cm} \times 1 \mathrm{~cm}$ on the top of the swabbed cultures and incubated at $35^{\circ} \mathrm{C} \pm 2{ }^{\circ} \mathrm{C}$ for $24 \mathrm{~h}$ in both bacterial and yeast cultures. The zone of inhibition 
observed for various mats were then estimated to determine their antimicrobial efficiency. The assay was performed in two independent duplicates and the average zone of inhibition value was reported.

The Gel_pDA_Ag mat was also evaluated for their antimicrobial potential using growth inhibition assay following CLSI guidelines. For this assay, $10 \pm 0.2 \mathrm{mg}$ of the Gel_pDA_Ag mat was incubated in $2 \mathrm{~mL}$ of $\mathrm{MH}$ broth containing bacterial cultures (at $10^{6}$ $\mathrm{CFU} / \mathrm{mL}$ ) for $24 \mathrm{~h}$ at $37^{\circ} \mathrm{C}$. The bacterial culture without the mat was used as the positive control. After $24 \mathrm{~h}$ of incubation, one-log (10-fold) serial dilutions of the bacterial suspension (with and without the mat) were prepared in PBS and $100 \mu \mathrm{L}$ of each dilution was pourplated on MHA plates and incubated at $37^{\circ} \mathrm{C}$ for $24 \mathrm{~h}$ for colony-forming units (CFUs) enumeration. The antimicrobial data was reported as the $\log _{10}$ reduction in $\mathrm{CFU} / \mathrm{ml}$ for Gel_pDA_Ag mat in comparison to untreated control.

2.11. Biocompatibility evaluation and cell proliferation studies. For cytotoxicity assessment and cell proliferation studies of various gelatin mats, human dermal fibroblast cells (hDFs) and HaCaT (immortalized Keratinocytes) were first grown in DMEM medium (Gibco®) supplemented with $10 \%(\mathrm{v} / \mathrm{v})$ fetal bovine serum, $50 \mathrm{U} \mathrm{mL}^{-1}$ penicillin and $50 \mathrm{mg}$ $\mathrm{mL}^{-1}$ streptomycin in a humidified incubator at $37{ }^{\circ} \mathrm{C}$ and $5 \% \mathrm{CO}_{2}$. After 3 days, the cells were passaged once and allowed to proliferate for another 3 days before harvesting. For harvesting, cells were washed with $10 \mathrm{mM}$ PBS to remove non-adherent cells before undergoing trypsin-EDTA treatment and centrifugation at $300 \mathrm{rpm}$ for 5 minutes to obtain a cell pallet. Fresh complete medium was then added to dissolve the cell pallet and cell counting was performed using a haemocytometer. For cell seeding, mats were spun on $15 \mathrm{~mm}$ coverslips and were sterilized under UV light for 2 hours. 
For biocompatibility studies, hDFs were then seeded on various electrospun mats placed at the bottom of the 12 -well plates (Nunc $囚$ ) at the density of $8 \times 10^{3}$ cells per well. CellTiter $96{ }^{\circledR}$ Aqueous One solution cell proliferation assay kit (Promega) was used to determine cell viability according to the manufacturer's instruction. Briefly, cells growing on the mat-coated coverslips placed in a 12-well plate containing $500 \mu \mathrm{L}$ of cell culture medium for $24 \mathrm{~h}$ were incubated with $50 \mu \mathrm{L}$ of MTS tetrazolium solution at $37^{\circ} \mathrm{C}$ for $2 \mathrm{~h}$. In this assay, metabolically active cells react with the tetrazolium salt present in MTS reagent and thus produce a soluble purple formazan dye with absorption maxima at $490 \mathrm{~nm}$. After $2 \mathrm{~h}$, the absorbance was recoreded at $490 \mathrm{~nm}$ using a microplate reader (Infinite M200 Pro, Tecan, Mannedorf, Switzerland) and the relative cell viability was calculated. Each treatment was performed in three independent triplicates. For confocal imaging, mats were washed with PBS after $24 \mathrm{~h}$ of cell growth to remove the non-adherent cells and the adherent cells were fixed with 3\% paraformaldehyde. Subsequently, the cells were fluorescently labeled with Alexa Fluor 569 phalloidin (Molecular Probes ${ }^{\circledR}$ ) and FITC conjugated anti- $\alpha$-tubulin to visualize cellular morphologies and Hoechst 33342 to visualize nuclei. Coverslips were then mounted on glass slides using Fluoromount ${ }^{\mathrm{TM}}$ and the confocal imaging was conducted by a Zeiss LSM800 laser scanning microscope (Carl Zeiss Microimaging Inc., NY, USA) using a $40 \times$ oil immersion objective lens. At least 20 different microscopic fields were analyzed for each sample.

For performing cell adhesion and prolifertaion studies for Gel_pDA_Ag and Gel_pDA_Zn mats, the samples were placed in 24-well plates and secured with stainless steel rings to prevent them from lifting off from the coverslips. Subsequently, the mats were washed with PBS twice for 15 minutes to remove debris and residual solvent before being soaked in complete media overnight for conditioning. Both hDFs and HaCaT cells were then seeded at a density of $8 \times 10^{3}$ cells per well and a plain coverslip served as a positive control. 
At Days 1, 4 and 7 post seeding (p.s.), cell proliferation on the mats was assessed by MTS assay as described earlier. To visualize cellular morphologies on various substrates, the media was removed from the wells at day 7 p.s., and washed once with PBS. Subsequently, the cells were then fixed with $4 \% \mathrm{v} / \mathrm{v}$ formaldehyde. After fixation, cells were permeabilised with $0.3 \% \mathrm{v} / \mathrm{v}$ Triton X-100 and subsequently washed thrice with PBS to remove residual detergent. Cells were then stained with Alexa Fluor 647-Phalloidin (actin filaments) and Hoesht (nuclei). Confocal imaging was then performed as discribed above. To evaluate the cellular morphology and adhesion on the mats, FE-SEM (JEOL - JSM6701F, the Netherlands) analysis was used. Initially, complete media was removed from the wells and cells were washed with PBS. Cells were then fixed using 3\% v/v glutaraldehyde. After fixation, subsequent dehydration of the cellular constructs was done using increasing concentrations of diluted ethanol followed by absolute ethanol, and finally with HMDS. The samples were then sputter coated with platinum (JEOL JSC-1200 fine coater, Japan) and viewed at an accelerating voltage of $10 \mathrm{kV}$.

\section{RESULTS AND DISCUSSION}

\subsection{Effect of metal ions on electrospinnability and morphology of as-electrospun gelatin}

mats. We first studied the effect of metal ions and dopamine alone and then their combined effect on electrospinning process parameters and fiber morphology. Previous studies have reported the effects of metal ions and salts on the morphology of electrospun gelatin nanofibers. ${ }^{24,25}$ A decrease in the diameter of as-electrospun gelatin nanofibers was noted in the presence of di/mono-valent ions $\left(\mathrm{Ca}^{2+}, \mathrm{Na}^{+}\right.$or $\left.\mathrm{K}^{+}\right)$in the dope solution owing to the enhanced Coulomb interaction forces during electrospinning. ${ }^{24,25}$ To infer the effect of metal ions on nanofibers, conditions were optimized to generate bead-free fibers and the morphological effects were ascertained by determining the average diameter of the nanofibers. Table 2 shows that the presence of metal ions in the dope solution strongly 
influenced the electrospinning parameters. In the presence of $\mathrm{Ag}^{+}$and $\mathrm{Ca}^{2+}$ ions in the dope solution, decreasing the flow rate conferred bead-free nanofibers whereas a higher field strength was required in the presence of $\mathrm{Mg}^{2+}$ ions. However, for $\mathrm{Zn}^{2+}$ a lower field strength and flow rate were required to achieve optimum electrospinnability. 


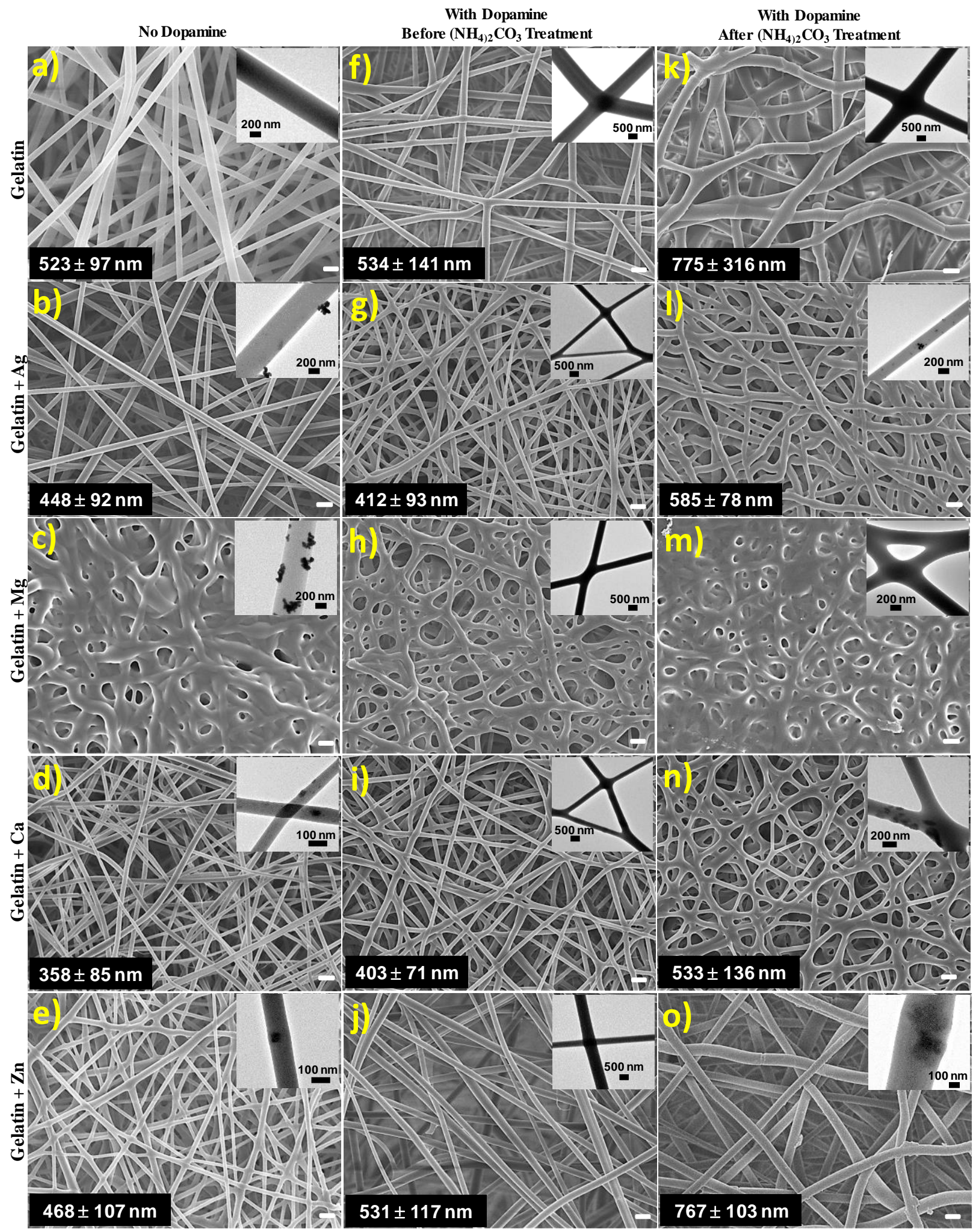

Figure 1. Field emission scanning electron micrographs of electrospun gelatin mats. a) ES_Gel, b) Gel_Ag, c) Gel_Mg, d) Gel_Ca, e) Gel_Zn, f) Gel_DA, g) Gel_DA_Ag, h) Gel_DA_Mg, i) Gel_DA_Ca, j) Gel_DA_Zn, k) Gel_pDA, 1) Gel_pDA_Ag, m) Gel_pDA_Mg, n) Gel_pDA_Ca, o) Gel_pDA_Zn. Scale bar $=1 \mu \mathrm{m}$. Inset in the figures shows the TEM images for the respective sample and the number written on the bottom-left corner of each SEM image corresponds to its enumerated average diameter value. 
SEM studies indicated the formation of smooth gelatin nanofibers with an average diameter of $522 \pm 97 \mathrm{~nm}$ (Fig. 1a). Incorporating metal ions into the gelatin solution was found to have varying effects on the morphologies and diameters of the gelatin nanofibers (Figure 1b-e). In the presence of $\mathrm{Ag}^{+}$and $\mathrm{Ca}^{2+}$ ions, the average diameter of nanofibers decreased substantially when compared to pristine gelatin mats (Figure 1b and d, Figure S2). The nanofibers formed upon addition of $\mathrm{Zn}^{2+}$ ions displayed "welded junctions" at the fiber cross over points with a marginal decrease in the average diameter in comparison to pristine gelatin fibers (Figure 1e). Reduction in the average diameter of gelatin nanofibers upon integration of metal ions could be due to the enhanced conductivity of the electrospinning dope solution. The presence of metal ions resulted in generation of a charged solution jet which experiences greater coulombic interactions, resulting in thinning of the fibers. Similar decrease in average fiber diameters were previously unveiled for PEO and Gelatin/PCL nanofibers upon adding $\mathrm{Na}^{+}$ion and $\mathrm{Ca}^{2+}$ ions, respectively. ${ }^{24,25}$ Aggregation and random crosslinking of the gelatin nanofibers was observed upon addition of $\mathrm{Mg}^{2+}$ ions, leading to increased abundance of welded junctions and merged nanofibers (Figure 1c). This anomalous behavior could be attributed to the inherent ability of $\mathrm{Mg}^{2+}$ ions to form stable complexes/chelates with groups like $-\mathrm{COOH},-\mathrm{OH}$ and $-\mathrm{NH}_{2}$ available in gelatin which promoted inter-molecular interaction among gelatin molecules, leading to their accretion and thus their increased fiber diameter and crosslinked morphology. ${ }^{26}$ TEM images for metal ion loaded fibers, displayed in the insets, revealed the presence of loosely adhered metal salt aggregates on the surface of the nanofibers.

Next, we investigated the electrospinnability of gelatin containing DA alone and DA with metal ions. As was observed before for metal ions, no change in field strength and flow rate was required for DA with silver, magnesium and calcium ions. However, higher field strength was required for the dope solution containing $\mathrm{DA}$ and $\mathrm{Zn}^{2+}$ ions than for the 
preparation of Gel_Zn nanofibers. SEM studies indicated the presence of few welded junctions at the intersecting points of Gel_DA nanofibers (Figure 1f) which increased dramatically upon adding $\mathrm{Ag}^{+}$and $\mathrm{Ca}^{2+}$ ions (Figure $1 \mathrm{~g}$ and $\mathbf{i}$ ), suggesting that these metal ions interacted with dopamine as well as gelatin molecules to induce enhanced fiber crosslinking. Interestingly, in the presence of magnesium and DA, the morphology of the mats looked similar to Gel_Mg (without dopamine) mat, though Gel_DA_Mg mats appeared more porous than the former. Analyzing the morphology of Gel_DA_Mg (Figure 1h) and Gel_Mg (Figure 1c) mats revealed systematic crosslinking/networking of gelatin nanofibers in the presence of DA and $\mathrm{Mg}^{2+}$ ions, whereas, random aggregation/agglomeration of gelatin nanofibers was observed with $\mathrm{Mg}^{2+}$ alone. Interestingly, the junction nanofibers formed in the presence of $\mathrm{Zn}^{2+}$ ions disappeared after dopamine incorporation in Gel_DA_Zn mats (Figure 1j), suggesting that DA-metal ions chelation may have prevented metal ion interaction with gelatin nanofibers. In support of this, UV spectra of DA recorded in the presence of $\mathrm{Zn}^{2+}$ ions indicated substantial shift of DA peak from 284 to $298 \mathrm{~nm}$, thus confirming dopamine- $\mathrm{Zn}^{2+}$ complexation. (Figure S3).

Analysis of the average diameter of the nanofibers indicated no apparent change in the diameter of nanofibers for Gel_DA in comparison to pristine ES_Gel mats. However, introducing $\mathrm{Ag}^{+}$and $\mathrm{Ca}^{2+}$ ions together with dopamine significantly decreased the average diameter of gelatin nanofibers, though $\mathrm{Zn}^{2+}$ ions had negligible influence on diameter distribution when compared to Gel_DA (Figure S2). On the other hand, the average diameter of Gel_DA_Mg nanofibers was found to be marginally higher than Gel_DA nanofibers. TEM images of the nanofibers showed an absence of metal aggregates/particulates on the fiber surface, which was previously observed for nanofibers prepared from gelatin containing metal ions (Figure 1g-j insets). Thus, the presence of DA in gelatin-metal ion dope solutions allowed smooth dispersion of metal ions, thus promoting the formation of smooth nanofibers. 
Recently, we reported that the ammonium carbonate exposure of $\mathrm{Ca}^{2+}$ ions and catecholamine containing collagen mats generated in situ mineralization and polycatecholamine cross-linking of electrospun collagen mats. ${ }^{27}$ This methodology (named as ammonium carbonate diffusion method, ADM) provided facile fabrication of nanofibrous mats with outstanding mechanical and osteoconductive properties. Thus, we investigated the influence of simultaneous in situ mineralization and polydopamine crosslinking of gelatin nanofibers containing DA and metal ions. SEM studies indicated a significant increase in welded junctions and extensive branching of the nanofibers after ADM, confirming fiber crosslinking through oxidative polymerization of dopamine i.e. transformation of dopamine to polydopamine (pDA) (Figure 1k-o). In general, the average diameter of the nanofibers increased significantly for all the mats in comparison to mats containing metal ions only. When compared to Gel_pDA mats, the average diameter of the crosslinked mats remained unaltered for Gel_pDA_Zn mats, whereas a decrease was observed for Gel_pDA_Ag and Gel_pDA_Ca mats (Figure S2c). TEM images also suggested the formation of sparsely distributed mineral particles inside along the length of the nanofibers for Gel_pDA_Ag, Gel_pDA_Ca, and Gel_pDA_Zn mats. Thus, morphological analysis confirmed the formation of smooth $\mathrm{pDA}$ coating and mineralization of gelatin nanofibers after ADM. Contrary to our methodology, functionalization of electrospun nanofibers with pDA by conventional Tris- $\mathrm{HCl}$ route followed by exposure to silver ions, often resulted in rough surfaces with heterogeneous aggregates of $\mathrm{pDA}$ and silver nanoparticles, whereas incorporation of dopamine and metal ions followed by subsequent exposure to ADM generated smooth pDA coating and crosslinking of electrospun gelatin and mineralization in situ. $^{28-30}$

\subsection{Effect of metal ions on bonding environment of dopamine loaded gelatin and pDA}

crosslinked mats. Next, we analyzed the bonding environment and composition of metal and 
dopamine incorporated gelatin mats before and after ADM treatment by XPS. High resolution $\mathrm{C} 1 \mathrm{~s}, \mathrm{~N}$ 1s, $\mathrm{O}$ 1s, $\mathrm{Cl} 2 \mathrm{p}, \mathrm{Ag} \mathrm{3d}, \mathrm{Mg} 2 \mathrm{p}, \mathrm{Ca} 2 \mathrm{p}$ and $\mathrm{Zn} 2 \mathrm{p}$ spectra for different samples are shown in Figure 2a-h. All the mats revealed the presence of C 1s, N 1s and O 1s peaks due to the presence of carbon, nitrogen and oxygen moieties in gelatin, dopamine and polydopamine. On the other hand, $\mathrm{Ag} 3 \mathrm{~d}, \mathrm{Mg} 2 \mathrm{p}, \mathrm{Ca} 2 \mathrm{p}$ and $\mathrm{Zn} 2 \mathrm{p}$ peaks also turned up in specific samples where the treatment of these mats was performed using their corresponding metal salts (Figure 2e-h). Although the Ag 3d peak was relatively weaker than $\mathrm{Mg} 2 \mathrm{p}, \mathrm{Ca} 2 \mathrm{p}$ and $\mathrm{Zn} 2 \mathrm{p}$ peak for both $\mathrm{AC}$ treated and untreated samples, the observation of different foreign elements ( $\mathrm{Ag}, \mathrm{Mg}, \mathrm{Ca}$ and $\mathrm{Zn}$ ) in various core level spectra confirmed the presence of metal ions in gelatin mats.
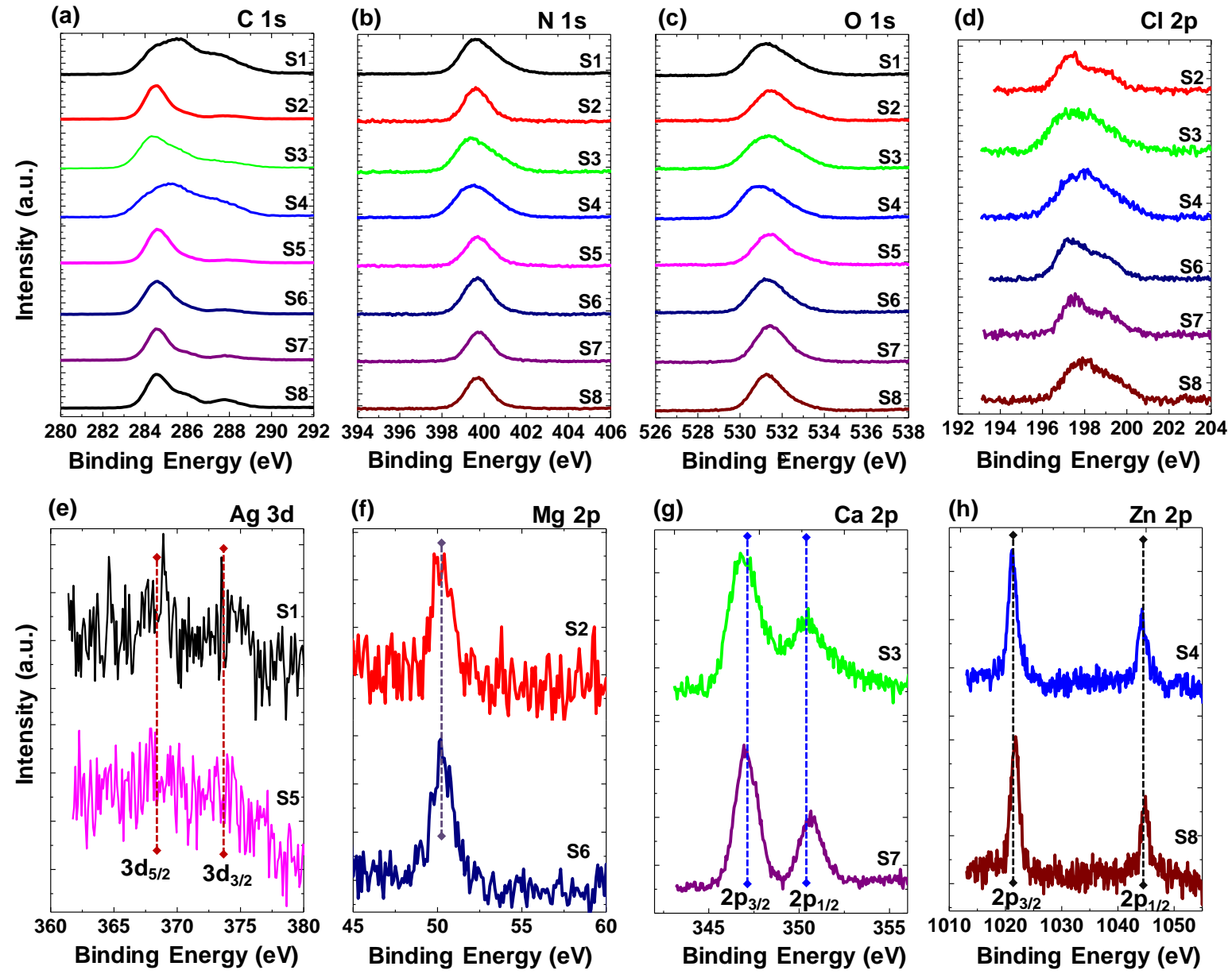

Figure 2. High resolution (a) C 1 s, N 1s (b), O 1s (c), Cl 2p (d), Ag 3d (e), Mg 2p (f), Ca 2p (g) and $\mathrm{Zn} 2 \mathrm{p}$ (h) for different composite structures. Herein S1- Gel_DA_Ag, S2- 
Gel_DA_Mg, S3-Gel_DA_Ca, S4-Gel_DA_Zn, S5-Gel_pDA_Ag, S6-Gel_pDA_Mg, S7Gel_pDA_Ca, S8-Gel_pDA_Zn.

As one of the key aims of our study was to unveil the effect of incorporating metal ions on the dopamine polymerization and $\mathrm{pDA}$ crosslinking of gelatin nanofibers, we performed deeper investigations on various bonding patterns in different metal incorporated samples. For comprehensive analysis, the deconvolution of high resolution $\mathrm{C}$ 1s and $\mathrm{N} 1 \mathrm{~s}$ core level spectra was performed using various Gaussian-Lorentzian components, Figure 3a and b. For reference, the $\mathrm{C}$ 1s and $\mathrm{N}$ 1s spectra of Gel_DA was also included. The deconvolution of $\mathrm{C} 1 \mathrm{~s}$ spectra revealed four peaks, namely $\mathrm{C}_{1}, \mathrm{C}_{2}, \mathrm{C}_{3}$ and $\mathrm{C}_{4}$, which are assigned to $\mathrm{C}-\mathrm{C} / \mathrm{C}-\mathrm{H}, \mathrm{C}-\mathrm{N}, \mathrm{C}-\mathrm{O}$ and $\mathrm{C}=\mathrm{O}$ bonding, respectively. ${ }^{27,31-33}$ On the other hand, the deconvolution of $\mathrm{N} 1 \mathrm{~s}$ spectra resulted into three peaks, namely $\mathrm{N}_{1}, \mathrm{~N}_{2}$, and $\mathrm{N}_{3}$, which were allotted to $\mathrm{R}_{2} \mathrm{NH}, \mathrm{RNH}_{2}$ and $\mathrm{C}=\mathrm{NR}$ bonding, respectively. ${ }^{27,31-33}$ The examination of these peaks, especially $\mathrm{C}=\mathrm{NR}$ bonding $\left(\mathrm{N}_{3}\right.$ peak) in $\mathrm{N}$ 1s spectra, can be used to understand the dopamine polymerization and pDA mediated crosslinking in gelatin. This was owed to the formation of more imine $(\mathrm{C}=\mathrm{NR})$ functionalities upon $\mathrm{pDA}$ formation and crosslinking of gelatin with pDA (Scheme 1). ${ }^{31}$ Hence, an area ratio method was used to quantify the bonding content and the results were summarized in Table 3 . The variation of $\mathrm{C}=\mathrm{NR}$ bonding in terms of absolute change and relative change for various samples was also estimated and plotted (Figure S4). Interestingly, metal ion incorporated mats (Gel_DA_X. where $\mathrm{X}=$ Metal ion) even before ammonium carbonate treatment showed comparatively higher $\mathrm{C}=\mathrm{NR}$ bonding than metal ion deprived Gel_DA mat (Figure S4). This could be attributed to metal ions triggering dopamine polymerization during electrospinning and activation of gelatin crosslinking even without performing AC treatment. Further increase in the $\mathrm{C}=\mathrm{NR}$ bonding was reported after ammonium carbonate treatment for Gel_pDA_Ag, Gel_pDA_Mg and Gel_pDA_Ca samples, indicative of increased pDA mediated crosslinking in these samples, concurring with the SEM results. Anomalously, relative change of $\mathrm{C}=\mathrm{NR}$ 
bonding was found to be highest for the Gel_pDA_Zn mat, although the SEM micrograph barely displayed any crosslinked morphology. To explain this incongruity, we hypothesis that the increase in $\mathrm{C}=\mathrm{NR}$ bonding in Gel_pDA_Zn mat is may be due to the formation of very small pDA oligomers that created a uniform coating on gelatin nanofibers, rather than crosslinking them, leading to increased fiber diameter $(767 \pm 103 \mathrm{~nm})$ compared to $\mathrm{AC}$ untreated Gel_DA_Zn mat $(531 \pm 117 \mathrm{~nm})$. This reasoning was also supported by the shifting of dopamine peak from $280 \mathrm{~nm}$ (monomeric peak) to $298 \mathrm{~nm}$ (small oligomer peak) as reported earlier by Wu et al (Figure S3). ${ }^{34}$ 
(a)
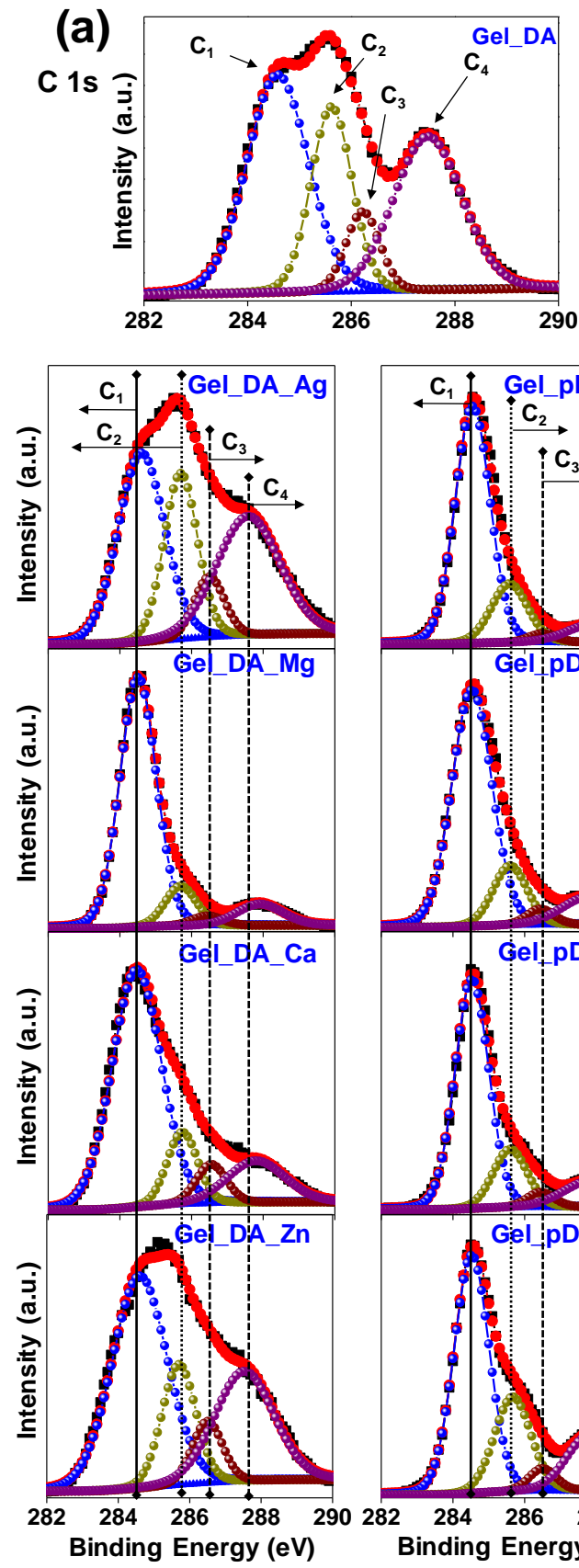
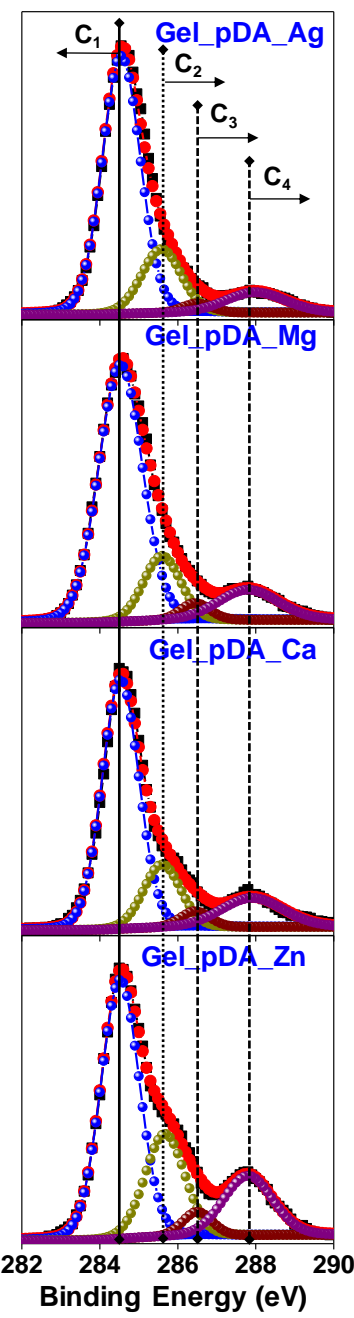

(b)
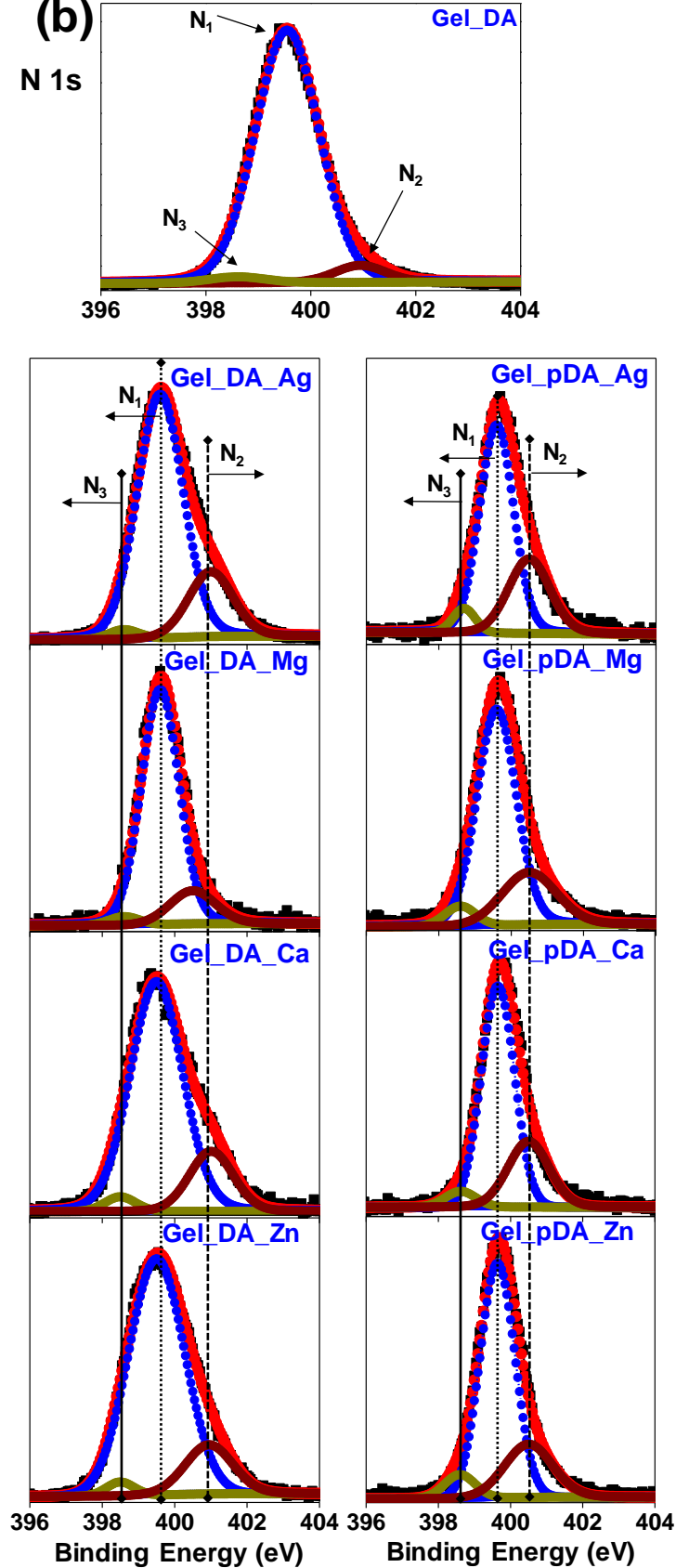

Figure 3. Deconvolution of high resolution a) $\mathrm{C} 1 \mathrm{~s}$ and b) $\mathrm{N}$ 1s spectra for different composite structures.

We have also studied extensively the core level spectra, namely Ag 3d, Mg 2p, Ca 2p and $\mathrm{Zn} 2 \mathrm{p}$, to reveal the metal bonding state in the nanofibrous composite mats (Figure 2eh). High resolution $\mathrm{Ag} 3 \mathrm{~d}$ spectra (Figure 2e) of Gel_DA_Ag and Gel_pDA_Ag demonstrated $3 \mathrm{~d}_{5 / 2}$ peak at $~ 368.3-368.4 \mathrm{eV}$. Based on binding energy (BE) of $\mathrm{Ag} 3 \mathrm{~d}_{5 / 2}$ peak, 
we suggest Ag to be present in both forms; metallic Ag and Ag bonded to oxygen. ${ }^{35}$ Similar behavior was observed while examining $\mathrm{Mg} 2 \mathrm{p}$ spectra where mats without and with $\mathrm{AC}$ treatment showed peaks at similar BE. It is well known that the peak position of $\mathrm{Mg}$ shifts toward higher $\mathrm{BE}$ side when $\mathrm{Mg}$ is bonded to oxygen. ${ }^{36,37}$ The $\mathrm{BE}$ position for $\mathrm{Mg}$ in metallic state was reported at around 49.4-49.6 eV while the $\mathrm{BE}$ for $\mathrm{Mg}$ bonded to oxygen can be in the range of $\sim 50.3-51 \mathrm{eV}$ and above. ${ }^{36,37}$ Thus, based on the peak position of our $\mathrm{Mg} 2 \mathrm{p}$ spectra, we expect the presence of $\mathrm{Mg}$ in both metallic and $\mathrm{Mg}$ bonded to oxygen states. To directly probe various bonding states in $\mathrm{Mg} 2 \mathrm{p}$ spectra, we performed deconvolution of Gel_DA_Mg and Gel_pDA_Mg (Figure S5a). During the deconvolution, we followed the work by Corneille et al. who assigned $\mathrm{Mg}$ metallic peak at $49.6 \mathrm{eV}$ and $\mathrm{Mg}$ bonded to oxygen peak at $50.8 \mathrm{eV} \cdot{ }^{36}$ In our case, the deconvolution of $\mathrm{Mg} 2 \mathrm{p}$ spectra for both the samples revealed two major distinct peaks namely $\mathrm{M}_{1}(49.7 \mathrm{eV})$ and $\mathrm{M}_{2}(50.75 \mathrm{eV})$ corresponding to metallic $\mathrm{Mg}$ and $\mathrm{Mg}$ bonded to oxygen, respectively. In addition, a weak $\mathrm{M}_{3}(52.0 \mathrm{eV})$ peak was observed toward slightly higher BE side which was also resulted from bonding of $\mathrm{Mg}$ with oxygen. We used an area ratio method to calculate the amount of $\mathrm{Mg}$ in metallic and $\mathrm{Mg}$ bonded to oxygen states, Table 3. From the results, we found that the bonding of $\mathrm{Mg}$ with oxygen increased after AC treatment which was expected to increase the robustness of produced nanofibers.

Furthermore, for the $\mathrm{Zn}$ containing samples, we observed from $\mathrm{Zn} 2 \mathrm{p}$ spectra that the $\mathrm{Zn} 2 \mathrm{p}_{3 / 2}$ and $\mathrm{Zn} 2 \mathrm{p}_{1 / 2}$ peaks experienced shifts toward higher BE side after AC treatment (Gel_pDA_Zn) with respect to Gel_DA_Zn mat. This triggered us to further analyze the bonding states of $\mathrm{Zn}$ in these samples. Woll ${ }^{38}$ and Biesinger et al. ${ }^{39}$ suggested that metallic $\mathrm{Zn}$ and $\mathrm{Zn}$ bonded to oxygen (Zn-O) peaks appear at $\mathrm{BE}$ of $1021.4 \mathrm{eV}$ and $1021.7 \mathrm{eV}$, respectively. The marginal $\mathrm{BE}$ difference between the two states of $\mathrm{Zn}$ thus created complexity for bonding analysis of $\mathrm{Zn}$. Based on extensive literature survey, we observed 
that the metallic Zn peak usually appears at around 1021-1021.4 eV while Zn-O peak originates at around 1021.7-1022 eV and above. ${ }^{38-40}$ Upon closer inspection, we observed the presence of Zn 2p $p_{3 / 2}$ peak at $\sim 1021.1$ eV in Gel_DA_Zn which shifted to $\sim 1021.7-1021.8 \mathrm{eV}$ in Gel_pDA_Zn sample. These spectra suggest that $\mathrm{Zn}$ in these samples certainly exist in both metallic and oxide states. Therefore, we performed the deconvolution of $\mathrm{Zn} 2 \mathrm{p}_{3 / 2}$ spectra while fixing the $\mathrm{BE}$ of $1021.1 \mathrm{eV}$ for metallic $\mathrm{Zn}$ (peak $\mathrm{Z}_{1}$ ) and $\mathrm{BE}$ of $1021.8 \mathrm{eV}$ for $\mathrm{Zn}-\mathrm{O}$ (peak $\mathrm{Z}_{2}$ ) as shown in Figure S5b. In addition, a weak $\mathrm{Z}_{3}$ peak towards higher BE side was also observed in both the samples which could be assigned to $\mathrm{ZnCl}_{2}$ in addition to contribution of $\mathrm{Zn}-\mathrm{O}$ in this peak as well. ${ }^{38-40}$ The results clearly indicate enhanced $\mathrm{Zn}-\mathrm{O}$ bonding in case of Gel_pDA_Zn mats compared to Gel_DA_Zn mat (Table S1).

Next, we focused on $\mathrm{Ca} 2 \mathrm{p}$ spectra. The peak positions of various important $\mathrm{Ca}$ compounds in $\mathrm{Ca} 2 \mathrm{p}_{3 / 2}$ envelopes are observed at $346-6-347.1 \mathrm{eV}$ for $\mathrm{CaCO}_{3}$ and $\mathrm{CaO}$, at $347.5 \mathrm{eV}$ for $\mathrm{CaSO}_{4}$, at $347.6 \mathrm{eV}$ for $\mathrm{CaBr}$, at 348 for $\mathrm{CaCl}_{2}$, at $348.2 \mathrm{eV}$ for $\mathrm{Ca}\left(\mathrm{NO}_{3}\right)_{2}$, etc. $^{41,42}$ In our case, we observed Ca $2 p_{3 / 2}$ peak at $346.9-347$ eV for both the Gel_DA_Ca and Gel_pDA_Ca mats. These results therefore indicate that there was a possibility of $\mathrm{Ca}$ carbonate and oxide formation, despite carbonate peaks not present in $\mathrm{C}$ 1s spectra which may be due to the dominance of carbon (from gelatin) in the C 1s spectra. Overall, XPS analysis provided critical insights into the bonding environment of composites mats such as metal ion-triggered crosslinking of DA containing gelatin fibers and enhancement of crosslinking after AC treatment due to synergistic effects 
Table 3. Bonding content of different constituent peaks in $\mathrm{C} 1 \mathrm{~s}$ and $\mathrm{N} 1 \mathrm{~s}$ spectra for various samples.

\begin{tabular}{|c|c|c|c|c|c|c|c|}
\hline Bample & $\begin{array}{c}\text { C-C/C-H } \\
(\boldsymbol{\%})\end{array}$ & $\begin{array}{c}\text { C-N } \\
(\boldsymbol{\%})\end{array}$ & $\begin{array}{c}\text { C-O } \\
(\boldsymbol{\%})\end{array}$ & $\begin{array}{c}\text { C=O } \\
(\boldsymbol{\%})\end{array}$ & $\begin{array}{c}\mathbf{R}_{2} \mathbf{N H} \\
(\boldsymbol{\%})\end{array}$ & $\begin{array}{c}\text { RNH } \\
(\boldsymbol{\%})\end{array}$ & $\begin{array}{c}\text { C=NR } \\
(\boldsymbol{\%})\end{array}$ \\
\hline Gel_DA & 39.2 & 22.2 & 7.9 & 30.7 & 93 & 5.1 & 1.9 \\
\hline Gel_DA_Ag & 37 & 23 & 8 & 32 & 77.8 & 20 & 2.2 \\
\hline Gel_pDA_Ag & 78.3 & 10.7 & 2.5 & 8.5 & 83.2 & 14.2 & 2.6 \\
\hline Gel_DA_Mg & 67 & 12.5 & 7 & 13.5 & 80 & 17 & 3 \\
\hline Gel_pDA_Mg & 49 & 16.8 & 8 & 26.2 & 82.5 & 15 & 2.5 \\
\hline Gel_DA_Ca & 70 & 19 & 2 & 9 & 66 & 29 & 5 \\
\hline Gel_pDA_Ca & 70.4 & 15 & 3.2 & 11.4 & 71 & 24 & 5 \\
\hline Gel_DA_Zn & 66.5 & 17 & 3.5 & 13 & 68.5 & 26.5 & 5 \\
\hline Gel_pDA_Zn & 56 & 23 & 4 & 17 & 70 & 23 & 7 \\
\hline
\end{tabular}

\subsection{Effect of DA and metal ions on mechanical properties of electrospun gelatin mats.}

To confirm the observations that the presence of metal ions could trigger the oxidative polymerization of dopamine, we investigated the mechanical properties of the gelatin nanofibers prepared under various conditions (Table 4). Representative stress-strain curves used to extract four different tensile parameters are shown in Supporting Information (Figure S6). The results indicated that except for $\mathrm{Ca}^{2+}$ ions, the presence of other ions in the dope solution increased the Young's modulus of the nanofibers in comparison to pristine gelatin mats. Among the metal ions, $\mathrm{Mg}^{2+}$ conferred the maximum increase in tensile stress and stiffness, consistent with the network-like morphology of as-electrospun mats. The increase in tensile strength upon incorporation of $\mathrm{Ag}^{+}, \mathrm{Mg}^{2+}$ and $\mathrm{Zn}^{2+}$ ions was accompanied by concomitant loss of elastic properties, as indicated by significant decrease in tensile strain.

The presence of dopamine had a similar effect as the metal ions in enhancing the Young's modulus at the expense of elastic properties. To probe the effect of metal ions, we compared the mechanical properties of Gel_DA and metal ion-containing Gel_DA mats which revealed distinct results for different metal ions. The Young's modulus and tensile strength were significantly increased and elasticity was slightly increased for Gel_DA_Mg and Gel_DA_Ca mats with respect to Gel_DA mat. The nanofibers prepared from a dope 
solution containing $\mathrm{Ag}^{+}$ions and DA showed a decrease in tensile stiffness and increase in failure strain, thus transforming the brittle behaviour of Gel_DA mats into a ductile material. Among metal containing Gel_DA mats, Gel_DA_Zn mats displayed poorer tensile properties. This again supports our previous hypothesis that strong interactions among DA and $\mathrm{Zn}^{2+}$ discourage the metal-gelatin nanofiber interactions that thus compromises junction configuration/crosslinking. The presence of calcium ions together with dopamine conferred the maximum increase in tensile modulus and tensile strength than other ions, indicating superior reinforcing ability of calcium ions for dopamine loaded gelatin mats.

Table 4. Effects of metal ions on mechanical properties of electrospun nanofibers prepared under various conditions. The changes in the mechanical properties were compared with nanofibers prepared without any metal ions. Statistical significant differences were indicated by asterisks: *, $\mathrm{p} \leq 0.05 ; * *, \mathrm{p}<0.01 ; * * *, \mathrm{p}<0.001$ and $* * * *, \mathrm{p}<0.0001$ by t-test or 1 -way ANOVA.

\begin{tabular}{|c|c|c|c|c|}
\hline Sample $^{\dagger}$ & $\begin{array}{l}\text { Tensile } \\
\text { strength }(\sigma) \text {, } \\
\text { MPa }\end{array}$ & $\begin{array}{l}\text { Tensile modulus } \\
\left(E^{\prime}\right), \mathrm{MPa}\end{array}$ & Strain $\left(\varepsilon_{b}\right), \%$ & $\begin{array}{l}\text { Toughness } \\
\left(\mathbf{J}_{\text {lc }}\right), \text { MJ.m }\end{array}$ \\
\hline ES_Gel & $2.30 \pm 0.18$ & $62.9 \pm 9.0$ & $19.04 \pm 2.78$ & $0.23 \pm 0.07$ \\
\hline Gel_Ag & $3.80 \pm 0.34^{* 3 * 2 * 3}$ & $202.1 \pm 35.84^{* * * 3 * *}$ & $8.74 \pm 2.66^{* 3 * 3}$ & $0.19 \pm 0.05$ \\
\hline Gel_Mg & $4.2 \pm 0.67^{* * * 3 * *}$ & $188.5 \pm 25.31^{* * * * * *}$ & $5.44 \pm 1.05^{* * 3 * * *}$ & $0.11 \pm 0.02$ \\
\hline Gel_Ca & $3.39 \pm 0.22^{* * * *}$ & $69.08 \pm 8.67$ & $22.24 \pm 2.33$ & $0.54 \pm 0.10^{* * * *}$ \\
\hline Gel_Zn & $2.94 \pm 0.14^{*}$ & $182.2 \pm 24.6$ & 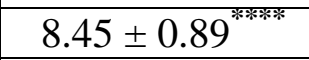 & $0.16 \pm 0.02$ \\
\hline Gel_DA & $2.56 \pm 0.22$ & $132.1 \pm 24.01$ & $5.278 \pm 1.04$ & $0.06896 \pm 0.012$ \\
\hline Gel_DA_Ag & $3.78 \pm 0.24$ & $90.86 \pm 12.41$ & $21.83 \pm 2.62^{* x_{1}}$ & $0.53 \pm 0.10^{* 3 \pi}$ \\
\hline Gel_DA_Mg & $5.63 \pm 0.86$ & $209.9 \pm 61.1^{* * *}$ & $8.70 \pm 1.87^{*}$ & $0.27 \pm 0.086^{* * *}$ \\
\hline Gel_DA_Ca & $9.34 \pm 2.39$ & $631.8 \pm 46.05^{* * * * * *}$ & $12.35 \pm 2.54^{* * * *}$ & $0.86 \pm 0.14^{* * * * *}$ \\
\hline Gel_DA_Zn & $2.22 \pm 0.14$ & $51.29 \pm 1.7^{* * *}$ & $8.24 \pm 1.08$ & $0.095 \pm 0.021$ \\
\hline Gel_pDA & $2.93 \pm 0.69$ & $157.1 \pm 36.1$ & $25.91 \pm 4.51$ & $0.52 \pm 0.14$ \\
\hline Gel_pDA_Ag & $6.97 \pm 0.58^{* * *}$ & $414.5 \pm 67.02^{*}$ & $8.02 \pm 4.93^{* 3 * 3 *}$ & $0.26 \pm 0.053^{*}$ \\
\hline Gel_pDA_Mg & $6.45 \pm 1.6^{* * *}$ & $461.6 \pm 161.2^{*}$ & $4.66 \pm 2.38^{* * * 3 *}$ & $0.16 \pm 0.04^{* * *}$ \\
\hline Gel_pDA_Ca & $12.4 \pm 0.46^{* * * * * *}$ & $778.2 \pm 123.3^{* * * * * *}$ & $6.09 \pm 0.493^{* * * *}$ & $0.46 \pm 0.10$ \\
\hline Gel_pDA_Zn & $3.253 \pm 0.49$ & $77.06 \pm 8.761$ & $16.46 \pm 2.89^{*}$ & $0.33 \pm 0.10$ \\
\hline
\end{tabular}

More dramatic changes in mechanical properties were observed after ammonium carbonate exposure of metal ions containing Gel_DA mats (Table 4). The results indicated that the ammonium carbonate exposure of gelatin mats containing $\mathrm{Ag}^{+}, \mathrm{Mg}^{2+}$ and $\mathrm{Ca}^{2+}$ ions (Gel_pDA_Ag, Gel_pDA_Mg and Gel_pDA_Ca) displayed more brittle-like behaviour than 
Gel_pDA and Gel_pDA_Zn mats which conferred both the brittle and ductile like stressstrain curves. Among the divalent cations, $\mathrm{Ca}^{2+}$ ions conferred the maximum improvement in mechanical properties followed by $\mathrm{Mg}^{2+}$ ions whereas $\mathrm{Zn}^{2+}$ ions decreased the tensile properties with respect to Gel_pDA. The improved mechanical properties of Gel_pDA_Ag, Gel_pDA_Mg and Gel_pDA_Ca, when compared to Gel_pDA, were attributed to pDA-metal ions mediated increase in inter-fiber interactions and cross-linking. In support of our observations, two previous studies reported similar enhancement in tensile properties of electrospun nanofibers by incorporation of mineral nanoparticles or nanotubes that were surface coated with polydopamine at low mineral content. ${ }^{43,44}$ However, poor mechanical properties of Gel_pDA_Zn with respect to Gel_pDA was due to formation of DA-Zn complex which in turn contributed to the loss of inter-fiber interactions and formation of welded junctions (Fig. S3).

3.4. Effect of metal ions on thermal properties of electrospun gelatin mats. Given the ability of metal ions to greatly influence the structure and bonding environment of gelatin nanofibers, the incorporation of metal ions was also expected to have considerable effect on thermal stability. Thermogravimetric analysis (TGA) and differential thermogravimetric analysis (DTA) were performed to assess the thermal stability of different electrospun gelatin-based mats. (Figure 4 \& Table 5) Pristine ES_Gel mats underwent weight loss in three stages: first stage weight loss $\left(\mathrm{W}_{1}\right)$ between 30 and $100{ }^{\circ} \mathrm{C}$, which represents the evaporation of physiosorbed water molecules; second stage weight loss $\left(\mathrm{W}_{2}\right)$ between 200 and $500{ }^{\circ} \mathrm{C}$, which specifies thermal degradation of gelatin nanofibers; and third stage weight loss $\left(\mathrm{W}_{3}\right)$ above $500{ }^{\circ} \mathrm{C}$, which corresponds to the carbonization of residual organic components. The peak weight loss temperatures for first, second and third stages are assigned as ${ }^{1} \mathrm{~T}_{\text {Dehydration, }}{ }^{2} \mathrm{~T}_{\max }$, and ${ }^{3} \mathrm{~T}_{\max }$, respectively. The $\mathrm{T}_{\mathrm{i}}$ (temperature at which the second stage weight loss begin), $\mathrm{T}_{1 / 2}$ (half decomposition temperature) and $\mathrm{W}_{\mathrm{Res}}$ (residual weight) were 
also estimated to get insight into the dopamine and metal ions interactions on the thermal properties of gelatin mats.
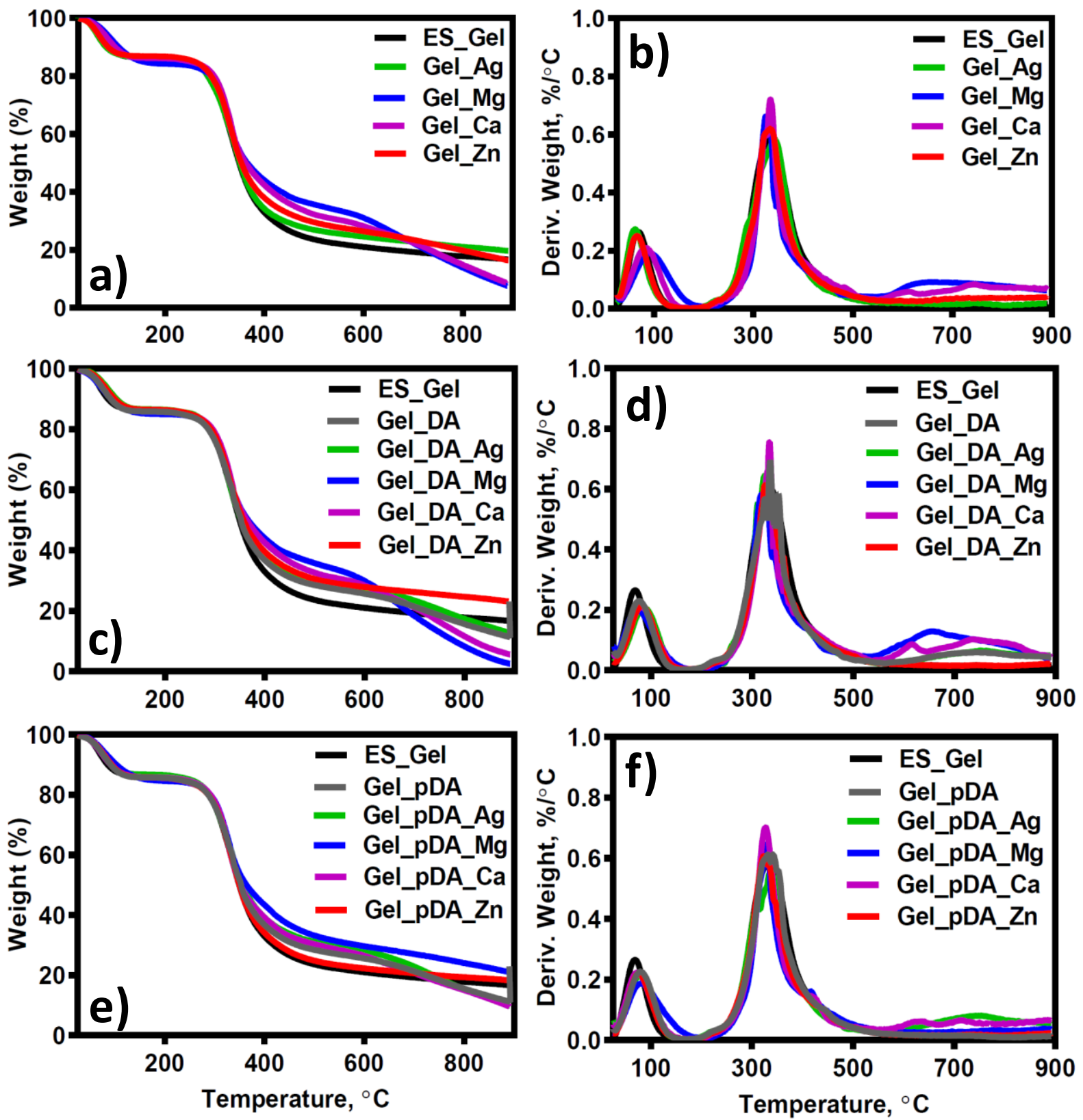

Figure 4. TGA and DTA curves for electrospun gelatin mats incorporated with ( $a$ and $b$ ) metal ions, (c and d) metal ions and dopamine, and (e and f) metal ions and polydopamine.

Thorough analysis of the TGA result leads us to following conclusions: i) Integrating metal ions (without dopamine) impacts the thermal properties of gelatin nanofibers (Figure 4a and b). Integration of alkaline earth metal ions $\left(\mathrm{Ca}^{2+}\right.$ and $\left.\mathrm{Mg}^{2+}\right)$ significantly enhances the ${ }^{1} \mathrm{~T}_{\text {Dehydration, }}, \mathrm{T}_{\mathrm{i}}$ and $\mathrm{T}_{1 / 2}$ temperatures (Table 5) with increase in $\mathrm{W}_{1}$ and $\mathrm{W}_{3}$ values (Table $\mathbf{S 2}$ ). 
These results indicate that $\mathrm{Ca}^{2+}$ and $\mathrm{Mg}^{2+}$ incorporation promotes and strengthens water interactions with the gelatin matrix and leads to higher ${ }^{1} \mathrm{~T}_{\text {Dehydration }}$ and $\mathrm{W}_{1}$ records. Further increases in the $T_{i}, T_{1 / 2}$ and $W_{3}$ values designate the stabilization of the gelatin nanofiber skeleton by $\mathrm{Ca}^{2+} / \mathrm{Mg}^{2+}$ ions that postponed its degradation to higher temperatures. On the contrary, transition metals $\left(\mathrm{Ag}^{+} / \mathrm{Zn}^{2+}\right)$ showed negligible effects on the thermal properties of gelatin nanofibers. Considering the ${ }^{1} \mathrm{~T}_{\text {Dehydration, }} \mathrm{T}_{\mathrm{i}}, \mathrm{T}_{1 / 2}$ and $\mathrm{W}_{3}$ parameters, the thermal stability of the metal incorporated mats follows the following order

$$
\text { Gel_Mg }{ }^{2+}>\text { Gel_Ca }{ }^{2+}>\text { Gel_Zn }{ }^{2+}>\text { Gel_Ag }{ }^{+}>\text {ES_Gel }
$$

ii) Adding dopamine alone also helped improve the thermal properties of gelatin nanofibers in term of boosted $\mathrm{T}_{\mathrm{i}},{ }^{1} \mathrm{~T}_{\text {Dehydration, }}, \mathrm{T}_{1 / 2}$, and $\mathrm{W}_{3}$ values, which was due to the enhanced interfiber interactions in the presence of dopamine molecules. iii) Integration of both metal ions and dopamine within the gelatin matrix further enhanced its thermal properties. Consistent with the trends in mechanical properties, Gel_DA_Mg, Gel_DA_Ag and Gel_DA_Ca showed significant enhancements in almost all the thermal parameters including ${ }^{1} \mathrm{~T}_{\text {Dehydration, }} \mathrm{T}_{\mathrm{i}}, \mathrm{T}_{1 / 2}$ and $\mathrm{W}_{3}$ values compared to gelatin and metal ion loaded mats without dopamine. This could be due to the remarkable complexation properties of $\mathrm{Mg}^{2+}, \mathrm{Ag}^{+}, \mathrm{Ca}^{2+}$ ions and their ability to promote dopamine polymerization which encourages the crosslinking of gelatin nanofibers, thus leading to improved thermal properties. Like without dopamine mats, $\mathrm{Zn}^{2+}$ ions with dopamine do not pose any significant impact on the thermal properties. Interestingly, all dopamine/metal enriched samples showed trifurcation in the ${ }^{2} \mathrm{~T}_{\max }$ peak supporting multiple interactions within the gelatin matrix due to the availability of both dopamine and polydopamine components. iv) All the crosslinked samples, particularly Gel_pDA_Ag and Gel_pDA_Ca, showed the best thermal parameters in terms of having high ${ }^{2} \mathrm{~T}_{\max }$ and ${ }^{3} \mathrm{~T}_{\max }$ values. In the crosslinked samples, trifurcations were transformed into bifurcations which may be due to the conversion of dopamine into polydopamine during crosslinking treatment. 
Table 5. Thermal properties of various electrospun gelatin mats.

\begin{tabular}{|c|c|c|c|c|c|}
\hline Sample Name & $\mathbf{T}_{\mathbf{i}}\left({ }^{\circ} \mathbf{C}\right)$ & ${ }^{\mathbf{1}} \mathbf{T}_{\text {Dehydration }}\left({ }^{\circ} \mathbf{C}\right)$ & ${ }^{{ }^{\mathbf{2}}} \mathbf{T}_{\mathbf{m a x}}\left({ }^{\circ} \mathbf{C}\right)$ & $\mathbf{T}_{\mathbf{1} / 2}\left({ }^{\circ} \mathbf{C}\right)$ & ${ }^{{ }^{3}} \mathbf{T}_{\mathbf{m a x}}\left({ }^{\circ} \mathbf{C}\right)$ \\
\hline ES_Gel & 180.1 & 69 & 335.8 & 349.3 & NA \\
\hline Gel_Ca & 192.8 & 85 & $335,324.3$ & 363.1 & $742.7,612.8$ \\
\hline Gel_Mg & 219.2 & 92.6 & $333,342.3$ & 367 & 663 \\
\hline Gel_Ag & 182 & 61.3 & 342.9 & 350.8 & NA \\
\hline Gel_Zn & 185 & 66.2 & 336.1 & 353.4 & NA \\
\hline Gel_DA & 190.9 & 77 & 324.3 & 352.3 & 746.3 \\
\hline Gel_DA_Ca & 192.8 & 81.4 & $335,345.4$ & 365 & 738 \\
\hline Gel_DA_Mg & 223.6 & 72.6 & $319,343.9$ & 367.6 & 614.7 \\
\hline Gel_DA_Ag & 204 & 85.7 & $327.3,313.1$ & 353 & 756 \\
\hline Gel_DA_Zn & 188.4 & 81.3 & $326.3,343.9$ & 358 & NA \\
\hline Gel_pDA & 182 & 79.4 & $330.7,341.5$ & 350 & NA \\
\hline Gel_pDA_Ca & 213 & 72.6 & $326.3,420$ & 352 & $628,713.5$ \\
\hline Gel_pDA_Mg & 217 & 81.4 & $330.7,416.3$ & 364.5 & NA \\
\hline Gel_pDA_Ag & 190.9 & 79.4 & $337.5,345.9$ & 355.8 & 747.7 \\
\hline Gel_pDA_Zn & 201.6 & 79.4 & 321.9 & 354.8 & NA \\
\hline
\end{tabular}

\subsection{Effect of metal ions on surface wettability of electrospun gelatin mats. Surface} wettability is one of the key determinants of cell adhesion and proliferation. ${ }^{45}$ Thus, we investigated how metal ions altered the surface wettability of ES_Gel and Gel_DA fibers before and after ADM. The surface wettability of all the mats was determined by measuring the water contact angle (WCA) in dynamic mode for 2 minutes. For simplicity, we compared the final WCA (after $2 \mathrm{~min}$ ) of all these samples (Figure 5). Pristine gelatin showed WCA of $25.5 \pm 3.2^{\circ}$ 


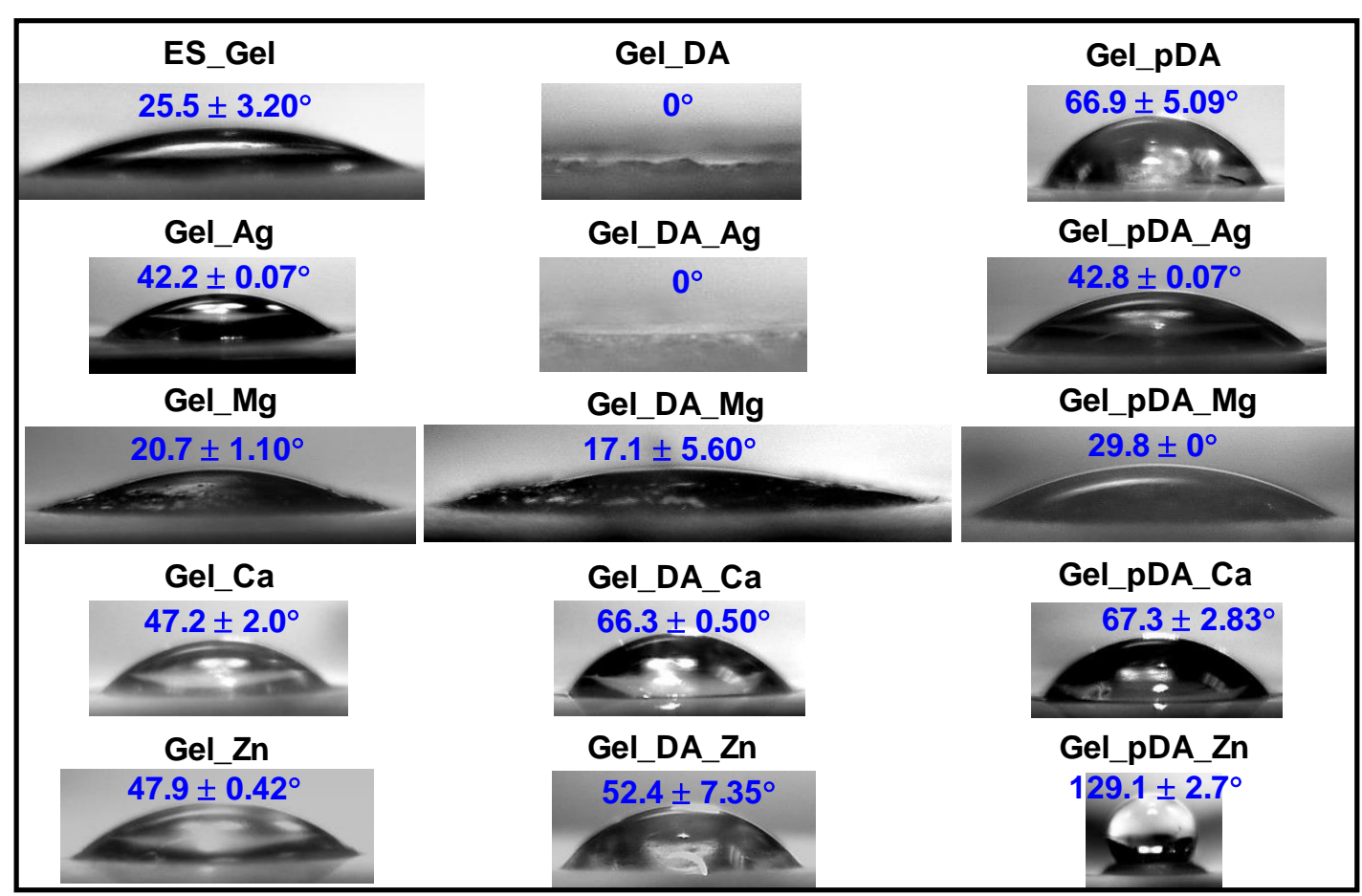

Figure 5. Photographs showing the water contact angle (WCA) on various electrospun gelatin mats captured after 2 mins of dropping the water drop.

Upon incorporating metal ions to pristine gelatin mats, an increase in WCA was observed for all the mats except Gel_Mg sample. This increase in the contact angle in metal ion incorporated gelatin mats may be due to the involvement of the hydrophilic groups ($\mathrm{OH} /-\mathrm{NH}_{2}$ ) of gelatin chains in forming chelates with the available metal ions as reported earlier by Tanaka. ${ }^{46}$ In contrast, the lower WCA of Mg-loaded mats could be due to the accessibility of more magnesium ions, owing to their small size, and their greater affinity to form hydrates. The WCA dropped to $0^{\circ}$ in Gel_DA mats due to the higher hydrophilicity provided by the polar groups in the dopamine structure. Incorporation of metal ions together with DA did not alter the final WCA values for Gel_DA_Ag mats, whereas the values increased for Gel_DA_Mg, Gel_DA_Zn and Gel_DA_Mg mats. These results suggest variable interactions between the biopolymer, DA and metal ions that might contribute to the differences in surface hydrophilicity. 
WCA values increased significantly for Gel_pDA mats when compared to ES_Gel or Gel_DA mats, indicating polydopamine coatings decreased the aqueous wettability of pristine gelatin mats, consistent with previous results. However, mats containing silver and magnesium (Gel_pDA_Ag \& Gel_pDA_Mg) displayed lower values than Gel_pDA. Among the divalent cations, Gel_pDA_Zn mats displayed the highest contact angle, indicating that co-ordination complex formed between the transition metal ion and pDA rendered the surface hydrophobic. $^{47}$ In support of this, we recorded the UV spectra of dopamine (DA) with or without divalent cations at $\mathrm{pH}$ 8.5. The absorption peak of dopamine at $284 \mathrm{~nm}$ was shifted to $297 \mathrm{~nm}$ in the presence of zinc indicating strong interactions between $\mathrm{Zn}^{2+}$ and DA whereas no apparent difference was observed in the presence of $\mathrm{Ca}^{2+}$ and $\mathrm{Mg}^{2+}$ ions (Fig. S3). Thus, the interaction of polydopamine with different metal ions conferred varying degrees of wettability: surface hydrophilicity increased in the presence of silver and magnesium, decreased in the presence of zinc, and remained unaltered in the presence of calcium.

\subsection{Cytocompatibility of composite mats for human dermal fibroblasts. The} cytocompatibility of the composite mats was ascertained in hDF by immunofluorescence confocal imaging. The hDFs cells were cultured on the mats for $24 \mathrm{~h}$ and the cellular integrity was assessed by staining the nuclei, $\alpha$-tubulin and actin of hDFs. In particular, we focused our attention on Gel_Ag and Gel_pDA_Ag as well as Gel_Zn and Gel_pDA_Zn mats to discern the effect of metal ions with and without pDA crosslinking. The hDF cells seeded on ES_Gel and Gel_pDA mats retained spindle shaped morphologies with intact cytoskeleton components and nuclei which were comparable to the cells seeded on tissue culture plates, indicating good biocompatibility of the mats (Figure 6). Cells seeded on Gel_Ag mats appeared rounded and truncated, confirming the cytotoxic effect of silver ions for hDFs. Interestingly, cells exposed to Gel_pDA_Ag mats retained their regular spindle-shaped morphology with intact cytoskeletal components and nuclei (Figure 6d), suggesting that the 
strong interactions between silver ion and pDA attenuated the toxic effect of silver. Cells cultured on both Gel_Zn and Gel_pDA_Zn mats appeared healthy. To further confirm these results, we determined the metabolic activity of hDFs, seeded on Gel_Ag and Gel_pDA_Ag mats by MTS assay. The results showed significant decrease in cell viability $(14.6 \pm 7.2 \%$, $\mathrm{p}<0.0001)$ of $\mathrm{hDF}$ s seeded on Gel_Ag mats, which was significantly improved in Gel_pDA_Ag mats $(74.0 \pm 17.4 \%, \mathrm{p}<0.001)$. Cell growth profile on Gel_Ca/Gel_Mg and Gel_pDA_Ca/Gel_pDA_Mg mats was not affected, confirming their lack of adverse effects for the mammalian cells (Figure S7). 


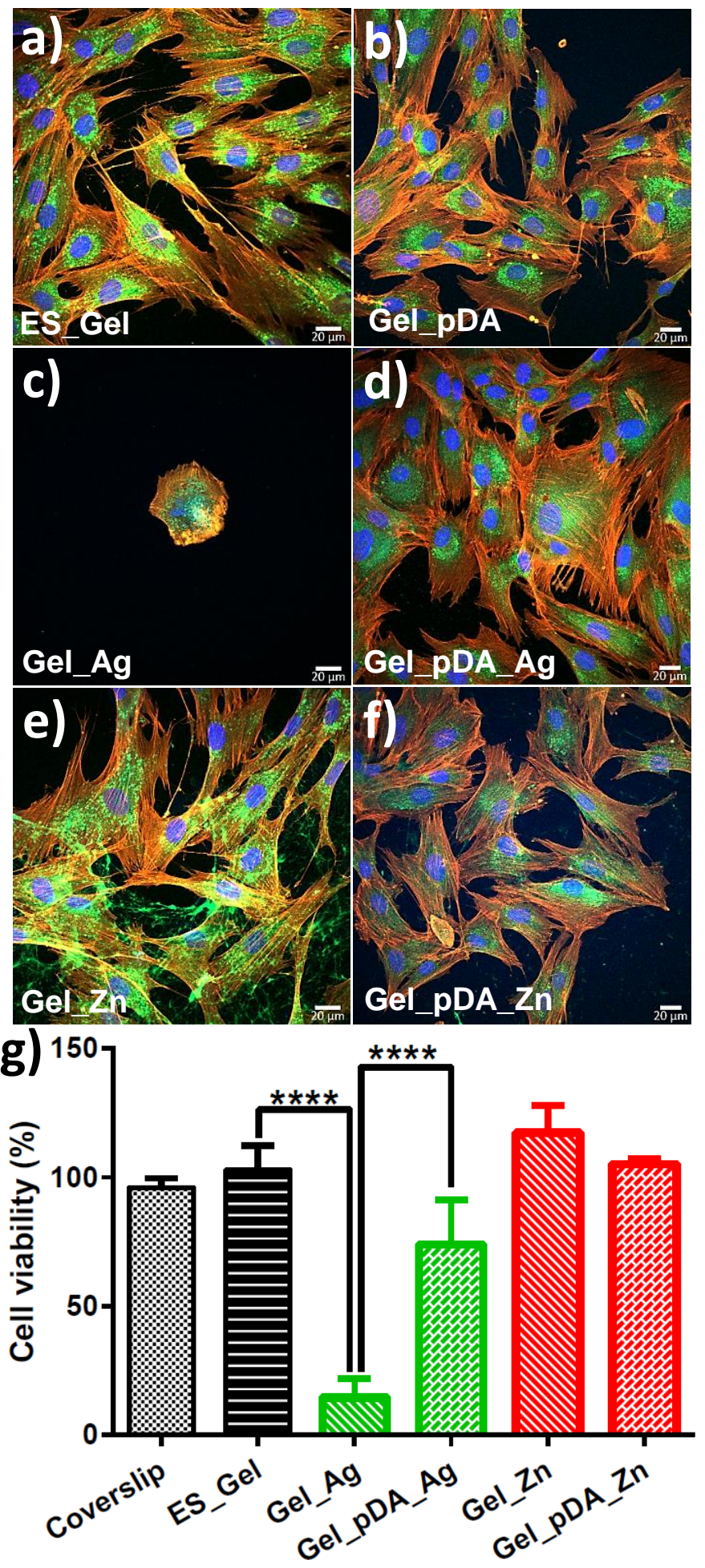

Figure 6. Cytocompatibility of mats in human dermal fibroblasts. (a-f) Confocal images of hDFs grown on different electrospun gelatin mat samples. Cells were cultured on ES_Gel (a), Gel_pDA (b), Gel_Ag (c), Gel_pDA_Ag (d), Gel_Zn (e), and Gel_pDA_Zn (f) for 24 h, stained for $\alpha$-tubulin (green), actin (red) and nuclei (blue) and imaged using confocal microscopy, 40X objective. At least 5 different fields per samples were imaged and a representative image is presented. Scale bar $=20 \mathrm{um}$. (g) Cell viability $(\%)$ of hDFs cultured 
on various mats for $24 \mathrm{~h}$ was determined using MTS-based assay and plotted, mean +/- SEM, $\mathrm{n}=3$ in triplicates.

Intrigued by the marked decrease in cytotoxicity of Gel_pDA_Ag and increased hydrophobicity of Gel_pDA_Zn mats, we then determined the cell proliferative properties of these mats, by monitoring the cell mitochondrial metabolic activity using MTS assay at day 1, day 4 and day 7 post seeding (p.s.) of HaCaT and hDFs. As shown in Fig. 7a, Gel_pDA_Ag mats displayed significant increase in the metabolic activity for HaCaT cell lines when compared to cells cultivated on Gel_pDA_Zn or coverslips. Zanette et al., reported that limited exposure of $\mathrm{HaCaT}$ cell lines to silver nanoparticles resulted in marked decrease in cell proliferative properties, suggesting heightened toxicity of silver. ${ }^{48}$ The lack of cytotoxic effects for $\mathrm{HaCaT}$ cell lines and the increased cell proliferative properties of the epidermal cell lines seeded on Gel_pDA_Ag mats augment our hypothesis that pDA chelation of silver decreased the toxicity and adverse effects of the ions on cell proliferative properties.

For hDFs, both Gel_pDA_Ag and Gel_pDa_Zn mats displayed similar increase in cell proliferation as that of cells cultivated on coverslips at day 1 and day 4 p.s. (Fig. 7b). A higher metabolic activity was observed for cells cultivated on coverslips at day 7 p.s., than Gel_pDA_Ag and Gel_pDA_Zn mats. It has been shown that sliver wound care products displayed significant cytotoxic effects on $\mathrm{HaCaT}$, primary keratinocytes and dermal fibroblasts. ${ }^{49,50}$ However, MTS results attained in the present study demonstrate excellent biocompatibility of Gel_pDA_Ag and Gel_pDA_Zn mats for skin cells. Immunofluorescent confocal and SEM images further indicate that cells (hDFs and HaCaT) seeded on Gel_pDA_Ag and Gel_pDA_Zn mats adhered in greater densities than coverslips (Fig. 7c). In particular, hDFs were well spread and formed a confluent monolayer on all the substrates even at day 4 p.s. Thus, the pDA crosslinking attenuated the toxicity and anti-proliferative 
properties of silver and these results establish the excellent biocompatibility of mineralized mats for skin cells.

a)

c)
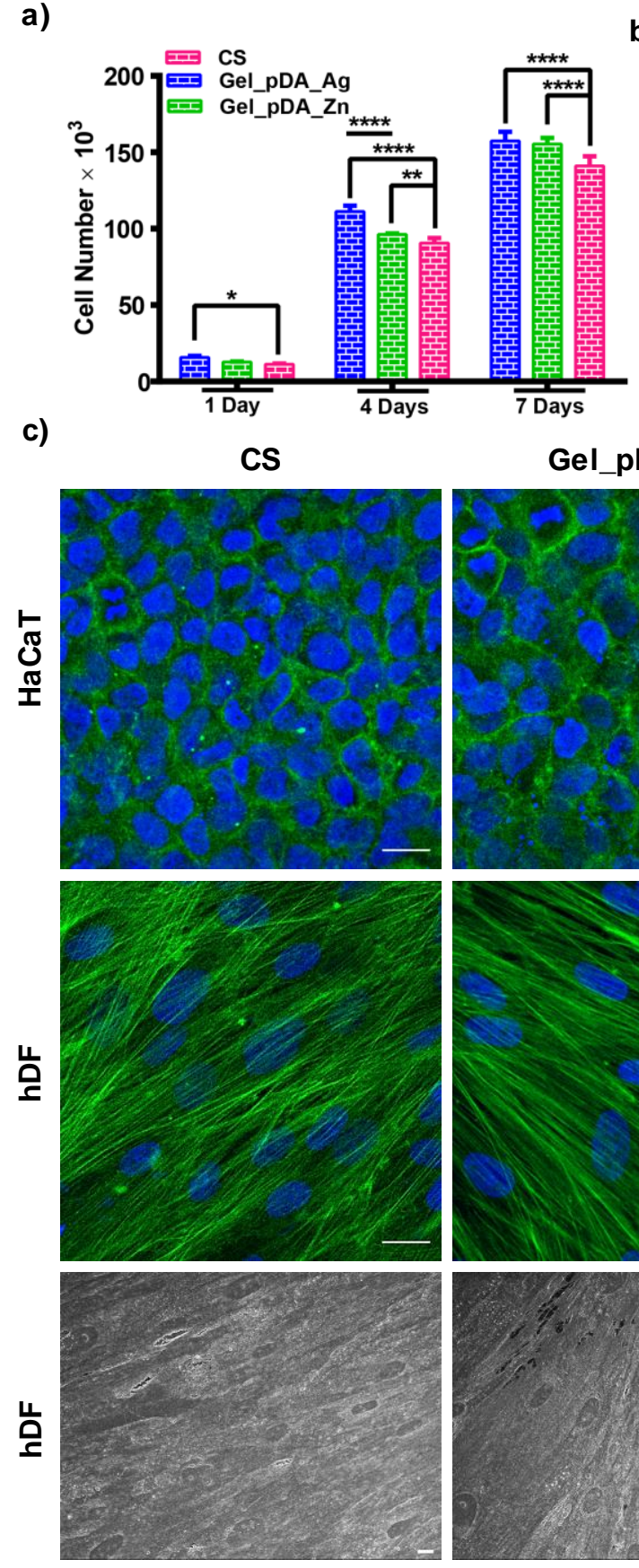

b)

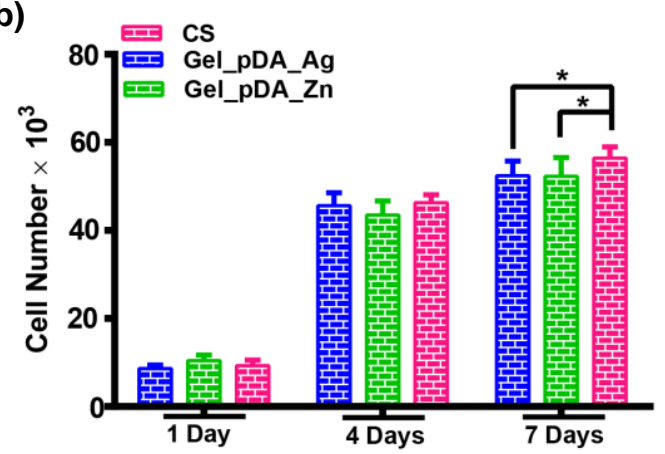

Gel_pDA_Ag

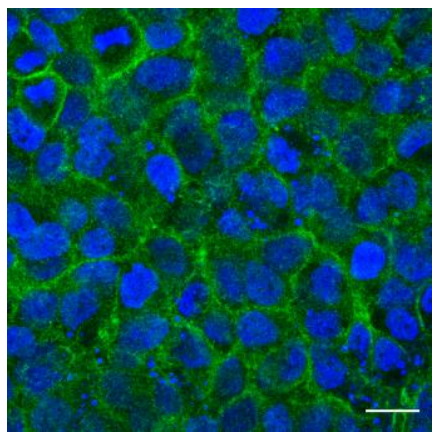

Gel_pDA_Zn

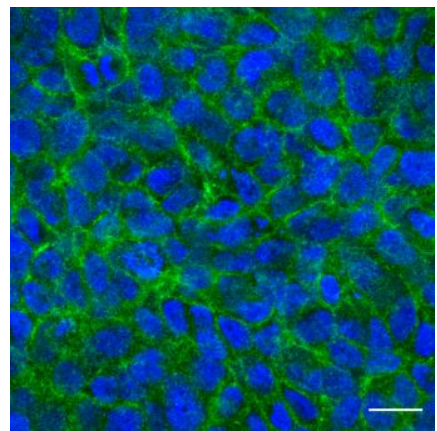

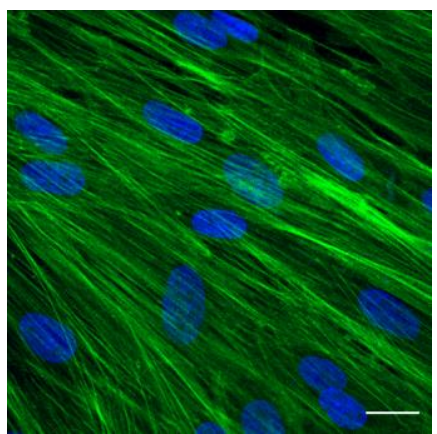
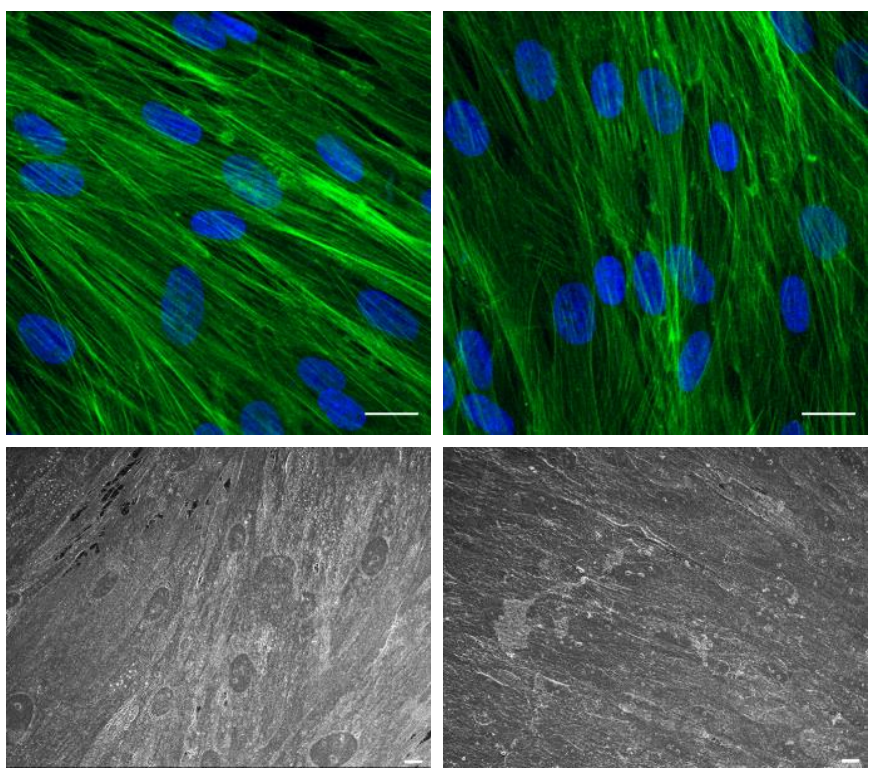

Figure 7. Cell proliferative properties of mineralized mats. Metabolic activity of HaCaT cell lines (a) and hDFs (b) seeded on Gel_pDA_Ag and Gel_pDA_Zn mats. Cells seeded on coverslips (CS) served as the control. c) Confocal images showing the morphology of $\mathrm{HaCaT}$ and hDFs seeded on Gel_pDA_Ag and Gel_pDA_Zn mats. Scale bar $=20 \mu \mathrm{m}$. The bottom panel shows the SEM images of hDFs seeded on various substrates. Scale bar $=20 \mu \mathrm{m}$. 
3.7. Antimicrobial Properties of Composite Mats. Recently, we reported that the polypyrogallol coating of catheters from a solution containing magnesium ions displayed potent antimicrobial and antibiofilm activities against MRSA strains. ${ }^{51}$ Based on the XPS data that metal ions did interact with polydopam ine, we determined the antimicrobial properties of Gel_pDA mats containing various metal ions by the disc diffusion method (Table 6). The range of pathogens included Gram-negative and Gram-positive bacteria, as well as yeasts. Gel_pDA mats did not display a clear zone of inhibition (ZOI) against any of the tested pathogens, confirming that pDA alone lacks antimicrobial properties, augmenting our previous results. ${ }^{52}$ Similarly, except for Gel_Ag mats, disc diffusion assay results indicated that gelatin mats containing other metal ions (Gel_Mg, Gel_Zn and Gel_Ca) lacked any antimicrobial activities (Figure S8). However, Gel_pDA_Mg mats displayed a clear ZOI against MRSA and $B$. cereus strains but lacked any antibacterial activity against VRE and $B$. subtilis strains (Table 6). Gel_pDA_Zn and Gel_pDA_Ca mats displayed clear ZOI against all the Gram-positive strains tested. Against the Gram-negative bacteria, no antimicrobial activity was detected for Gel_pDA_Ca mats, whereas Gel_pDA_Zn/Gel_pDA_Mg mats displayed contact inhibition as no bacterial growth was observed on the tops and bottoms of the mats. Gel_pDA_Ag mats displayed potent broad spectrum antimicrobial properties against the panel of Gram-negative/-positive and yeast strains. These results demonstrate that Ag-pDA chelation retained the antimicrobial activity of silver, whereas similar interactions with zinc, calcium and magnesium conferred potent antimicrobial properties.

To ascertain if silver complexation with pDA retained the bactericidal properties, we exposed the bacterial cells $\left(\sim 10^{6} \mathrm{CFU} / \mathrm{ml}\right)$ to Gel_pDA_Ag mats for $24 \mathrm{~h}$ under proliferative conditions and determined the viable bacteria. The results suggest $2-8 \log _{10}$ decrease in bacterial viability, depending on the nature of strains, confirming bactericidal properties of Gel_pDA_Ag (Table S3). Next, we investigated the long-term antimicrobial activity by 
determining ZOI for Gel_Ag and Gel_pDA_Ag mats against $P$. aeruginosa, following the protocol reported before. ${ }^{23,31}$ For Gel_Ag mats, burst release of silver ions resulted in an increase in ZOI values within $24 \mathrm{~h}$ which decreased with increasing soaking time in PBS (Fig. 8b). ZOI value for Gel_pDA_Ag mats, however, remained similar throughout the course of the study, and both the mats retained substantial antimicrobial properties even after 40-day of immersion in PBS.

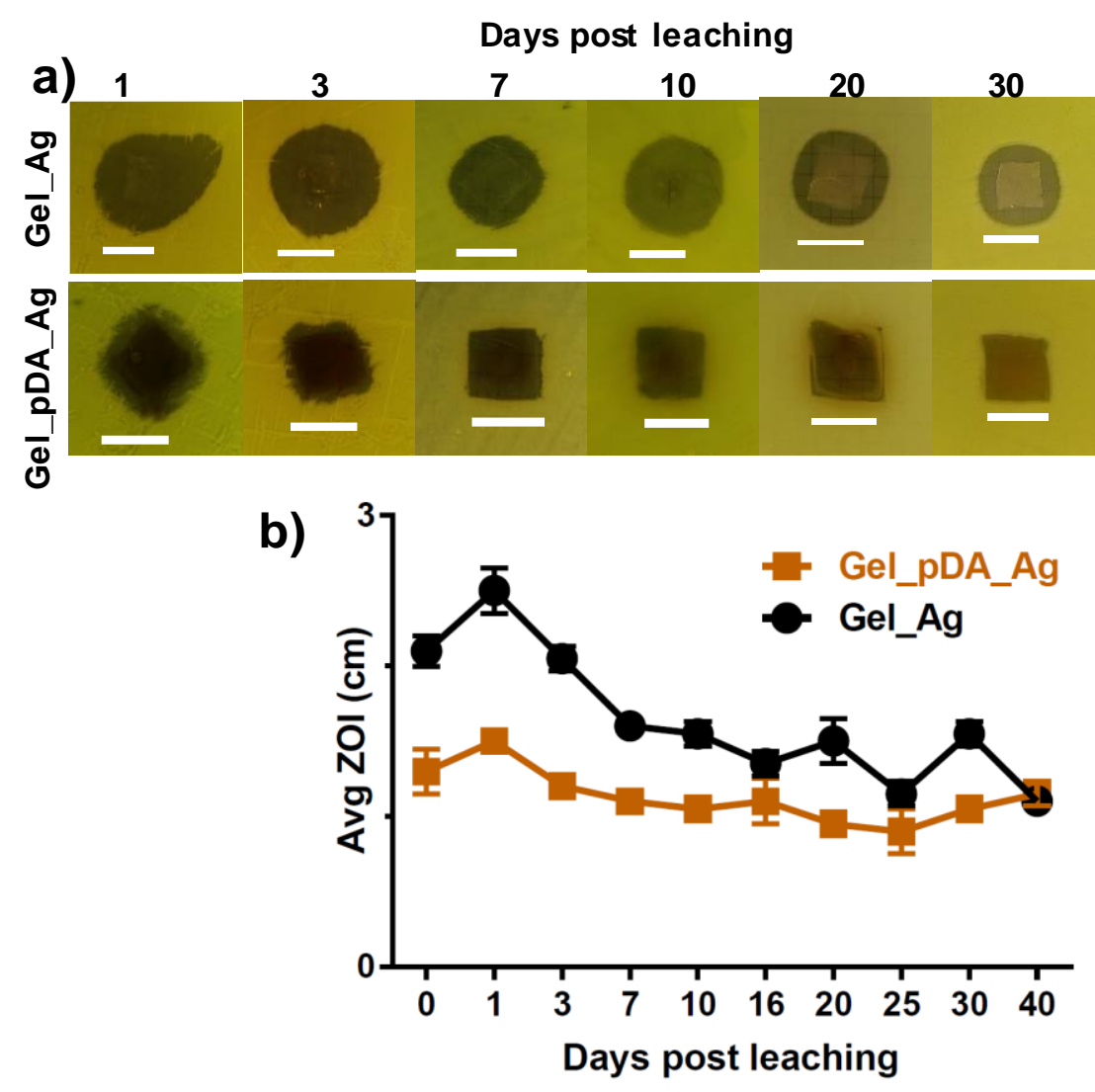

Figure 8. a) Representative digital photos showing the long-term antimicrobial activity of Gel_Ag and Gel_pDA_Ag mats against P. aeruginosa ATCC 9027 strains. b) Graph showing the changes in ZOI, after soaking in PBS for different time intervals. Note a slight increase in ZOI values for Gel_pDA_Ag mats immediately after immersion in PBS which later become consistent with increasing time. Each ZOI value represents an average of two independent experiments, determined by disc diffusion assay.

Together with XPS results, these observations demonstrate that the chelating ability of polydopamine allowed the controlled release of $\mathrm{Ag}^{+}$ions, thus attenuating its cytotoxicity for hDFs while retaining long-term antimicrobial activity. These observations corroborate with the results from others that polydopamine or polyDOPA coating following functionalization 
of antimicrobial ions such as $\mathrm{Cu}^{2+}$ or $\mathrm{Ag}^{+}$attenuated mammalian cell cytotoxicity while retaining antimicrobial properties..$^{28,53-55}$ It has been demonstrated that commercial wound dressings containing silver or chlorohexidine displayed heightened mammalian cytotoxic effects and anti-proliferative properties. ${ }^{50,56}$ Strategies like the one reported here using polycatecholamine coatings would represent a valuable proposition for better wound management. The synergistic antimicrobial effects of pDA with biologically relevant $\mathrm{Mg}^{2+}$, $\mathrm{Ca}^{2+}$ and $\mathrm{Zn}^{2+}$ ions may provide a simplistic approach towards bacterial decontamination wherein the use of antibiotics or antiseptics are restricted.

Table 6. Antimicrobial activity (in term of zone of inhibition) for various metal-ion loaded gelatin mats crosslinked with polydopamine against different microbial strains.

\begin{tabular}{|c|c|c|c|c|c|}
\hline Strains & GEL_pDA & GEL_pDA_Ag & GEL_pDA_Mg & GEL_pDA_Ca & GEL_pDA_Zn \\
\hline \multicolumn{6}{|c|}{ Gram Positive Bacteria } \\
\hline $\begin{array}{l}\text { Methicillin-resistant } \\
\text { Staphylococcus aureus } \\
\text { (MRSA) DM09808R }\end{array}$ & - & $3.5 \mathrm{~cm}$ & $3.0 \mathrm{~cm}$ & $2 \mathrm{~cm}$ & $2.1 \mathrm{~cm}$ \\
\hline MRSA 700699 & - & $3.1 \mathrm{~cm}$ & $4.1 \mathrm{~cm}$ & $2 \mathrm{~cm}$ & $2.4 \mathrm{~cm}$ \\
\hline B.cereus 11778 & - & $1.9 \mathrm{~cm}$ & $1.3 \mathrm{~cm}$ & $1.5 \mathrm{~cm}$ & $1.3 \mathrm{~cm}$ \\
\hline B.subtilis 6633 & - & $1.4 \mathrm{~cm}$ & - & $1.4 \mathrm{~cm}$ & $2.4 \mathrm{~cm}$ \\
\hline $\begin{array}{l}\text { Vancomycin- resistant } \\
\text { enterococci (VRE) } 1001\end{array}$ & - & $1.2 \mathrm{~cm}$ & - & $1.7 \mathrm{~cm}$ & $1.5 \mathrm{~cm}$ \\
\hline VRE 1002 & - & $1.6 \mathrm{~cm}$ & - & $1.1 \mathrm{~cm}$ & $1.3 \mathrm{~cm}$ \\
\hline \multicolumn{6}{|c|}{ Gram Negative Bacteria } \\
\hline P.aeruginosa 9027 & - & $2.1 \mathrm{~cm}$ & $1.4 \mathrm{~cm}$ & - & $1.6 \mathrm{~cm}$ \\
\hline P.aeruginosa 01 & - & $2.4 \mathrm{~cm}$ & $1.4 \mathrm{~cm}$ & - & $0.8 \mathrm{~cm}$ \\
\hline A.baumannii 19606 & - & $4.5 \mathrm{~cm}$ & $1.6 \mathrm{~cm}$ & - & $1.3 \mathrm{~cm}$ \\
\hline A.baumannii 1001 & - & $3.0 \mathrm{~cm}$ & $1.2 \mathrm{~cm}$ & - & $1 \mathrm{~cm}$ \\
\hline K.pneuтоniae DM4299 & - & $2.8 \mathrm{~cm}$ & $1.5 \mathrm{~cm}$ & - & $1.3 \mathrm{~cm}$ \\
\hline K.pneumoniae 10031 & - & $2.2 \mathrm{~cm}$ & $1.5 \mathrm{~cm}$ & - & $0.8 \mathrm{~cm}$ \\
\hline \multicolumn{6}{|c|}{ Yeast } \\
\hline $\begin{array}{l}\text { C.albicans } \\
\text { DF0001976R }\end{array}$ & - & $1 \mathrm{~cm}$ & - & - & $0.9 \mathrm{~cm}$ \\
\hline $\begin{array}{c}\text { C.albicans } \\
10231\end{array}$ & - & $1 \mathrm{~cm}$ & - & - & - \\
\hline
\end{tabular}




\section{Conclusions}

Crosslinking of gelatin nanofibers can be done via oxidation of dopamine to polydopamine under alkaline conditions. Using this knowledge, we have proposed a method to create a gelatin-based electrospun scaffold that is durable, water resistant, biocompatible and exhibits long lasting anti-microbial activity. We have observed that mats containing silver and zinc ions possess superior anti-microbial activity and also proposed that the interaction between magnesium and calcium ions with polydopamine can also confer good anti-microbial activity. With the rising incidences of antibiotic resistant pathogens, the mineralized antimicrobial mats with cell supportive properties can lower costs without adding other antimicrobial agents. Based on all the mentioned desirable properties, we propose the potential applications of these multifunctional nanofibrous mats as anti-infective wound dressings, benign tissue engineering scaffolds and safe inserts or implants with enhanced tissue regeneration properties.

\section{Supporting Information}

Figures showing the photographs of different gelatin solutions for fabricating electrospun mats, diameter distribution curves for different mats, UV-Visible absorbance plot showing dopamine interactions with different metal ions, variation of $\mathrm{C}=\mathrm{NR}$ bonding in different mats, deconvolution of $\mathrm{Mg} 2 \mathrm{p}$ and $\mathrm{Zn} 2 \mathrm{p}_{3 / 2}$ spectra for various composite mat samples, stressstrain curves for various mats, confocal images revealing the morphology of human dermal fibroblasts on various calcium and magnesium loaded gelatin mats and disc diffusion assay images showing the antimicrobial effectiveness of various electrospun gelatin mats. Tables showing bonding content of different constituent peaks in $\mathrm{Mg} 2 \mathrm{p}$ and $\mathrm{Zn} 2 \mathrm{p}$ spectra, thermal properties for various electrospun gelatin mats in term of weight loss and bacterial viability results for Gel_pDA_Ag mats. 


\section{Acknowledgements}

The authors thank the Translational and Clinical Research Flagship Program of the Singapore National Research Foundation (NMRC/TCR/008-SERI/2013), administered by the National Medical Research Council of the Singapore Ministry of Health. This work was supported by Co-operative Basic Research Grant from the Singapore National Medical Research Council (NMRC/CBRG/0048/2013) and SNEC Ophthalmic Technologies Incubator Program grant (Project no. R1181/83/2014) awarded to RL. This research is supported by the Singapore Ministry of Health's National Medical Research Council under its Centre Grant ProgrammeOptimization of core platform Technologies for Ocular Research (INCEPTOR)NMRC/CG/M010/2017_SERI. NKV acknowledges funding support from Lee Kong Chian School of Medicine, Nanyang Technological University Singapore Start-Up Grant (L0412290) and the Singapore Ministry of Education under its Singapore Ministry of Education Academic Research Fund Tier I (2015-T1-001-082). 


\section{References}

(1) Antibiotic / Antimicrobial Resistance. https://www.cdc.gov/drugresistance/

(2). Salwiczek, M.; Qu, Y.; Gardiner, J.; Strugnell, R. A.; Lithgow, T.; McLean, K. M.; Thissen, H. Emerging Rules for Effective Antimicrobial Coatings. Trends Biotechnol. 2014, $32(2), 82-90$.

(3) $\mathrm{Yu}, \mathrm{Q}$; $\mathrm{Wu}, \mathrm{Z}$; Chen, H. Dual-Function Antibacterial Surfaces for Biomedical Applications. Acta Biomater. 2015, 16, 1-13.

(4) Eckhardt, S.; Brunetto, P. S.; Gagnon, J.; Priebe, M.; Giese, B.; Fromm, K. M. Nanobio Silver: Its Interactions with Peptides and Bacteria, and its Uses in Medicine. Chem. Rev. 2013, 113 (7), 4708-4754.

(5) Harrison, J. J.; Ceri, H.; Turner, R. J. Multimetal Resistance and Tolerance in Microbial Biofilms. Nat. Rev. Microbiol. 2007, 5, 928.

(6) Harrison Joe, J.; Ceri, H.; Stremick Carol, A.; Turner Raymond, J. Biofilm Susceptibility to Metal Toxicity. Environ. Microbiol. 2004, 6 (12), 1220-1227.

(7) Pasquet, J.; Chevalier, Y.; Pelletier, J.; Couval, E.; Bouvier, D.; Bolzinger, M. A. The Contribution of Zinc Ions to the Antimicrobial Activity of Zinc Oxide. Colloids Surf., A 2014, 457, 263-274.

(8) Boonkaew, B.; Kempf, M.; Kimble, Roy.; Supaphol, Pitt.; Cuttle, Leila. Antimicrobial efficacy of a novel silver hydrogel dressing compared to two common silver burn wound dressings: Acticoat ${ }^{\mathrm{TM}}$ and PolyMem Silver ${ }^{\circledR}$, Burns. 2014, 40, 89-96.

(9) Rupp, M. E.; Fitzgerald, T.; Marion, N.; Helget, V.; Puumala, Susan.; Anderson, J. R.; Fey P. D. Effect of Silver-Coated Urinary Catheters: Efficacy, Cost-Effectiveness, and Antimicrobial Resistance, Am. J. Infect. Control 2004, 32, 445-450.

(10) Ewald, A.; Gluckermann, S. K.; Thull, R.; Gbureck, U. Antimicrobial Titanium/Silver PVD Coatings on Titanium. Biomed. Eng. Online 2006, 5, 22.

(11) Wilks, S. A.; Michels, H.; Keevil, C.W. The Survival of Escherichia Coli O157 on a Range of Metal Surfaces. Int. J. Food. Microbiol. 2005, 105, 445-454. 
(12) Wilks, S. A.; Michels, H.; Keevil, C.W. Survival of Listeria Monocytogenes Scott A on Metal Surfaces: Implications for Cross-contamination. Int. J. Food. Microbiol. 2006, 111, 93-98.

(13) Faundez, G.; Troncoso, M.; Navarrete, P.; and Figueroa, G. Antimicrobial Activity of Copper Surfaces against Suspensions of Salmonella Enterica and Campylobacter Jejuni. BMC Microbiol. 2004, 4, 1-7.

(14) Mehtar, S.; Wiid, I.; Todorov, S. D. The Antimicrobial Activity of Copper and Copper Alloys Against Nosocomial Pathogens and Mycobacterium Tuberculosis Isolated from Healthcare Facilities in the Western Cape: An In-Vitro Study. J. Hosp. Infect. 2008, 68, 4551.

(15) Warnes, S. L.; Keevil, C. W. Mechanism of Copper Surface Toxicity in VancomycinResistant Enterococci Following Wet or Dry Surface Contact. Appl. Environ. Microbiol. 2011, 77, 6049-6059.

(16) Noyce, J. O.; Michels, H.; Keevil, C.W. Potential Use of Copper Surfaces to Reduce Survival of Epidemic Meticillin-Resistant Staphylococcus Aureus in the Healthcare Environment. J. Hosp. Infect. 2006, 6, 289-297.

(17) Lin, Y. E.; Stourt, J. E.; Yu, V. L. Controlling Legionella in Hospital Drinking Water: An Evidence-Based Review of Disinfection Methods. Infect. Control Hosp. Epidemiol. 2011, $32,166-173$.

(18) Sridhar, R.; Lakshminarayanan, R.; Madhaivan, K.; Barathi, V. A.; Lim, K. C. L.; Ramakrishna, S. Electrosprayed Nanoparticles and Electrospun Nanofibers Based on Natural Materials: Applications in Tissue Regeneration, Drug Delivery and Pharmaceuticals. Chem. Soc. Rev. 2015, 44 (3), 790-814.

(19) Ko, E.; Lee, J. S.; Kim, H.; Yang, S. Y.; Yang, D.; Yang, K.; Lee, J.; Shin, J.; Yang, H. S.; Ryu, W.; Cho, S. -W. Electrospun Silk Fibroin Nanofibrous Scaffolds with Two-Stage Hydroxyapatite Functionalization for Enhancing the Osteogenic Differentiation of Human Adipose-Derived Mesenchymal Stem Cells. ACS Appl. Mater. Interfaces 2018, 10 (9), 76147625 . 
(20) Abrigo, M.; Mcarthur, S. L.; Kingshott, P. Electrospun Nanofibers as Dressings for Chronic Wound Care: Advances, Challenges, and Future Prospects. Macromol. Biosci. 2014, 14 (6), 772-792.

(21) Ruckh, T. T.; Oldinski, R. A.; Carroll, D. A.; Mikhova, K.; Bryers, J. D.; Popat, K. C. Antimicrobial Effects of Nanofiber Poly(Caprolactone) Tissue Scaffolds Releasing Rifampicin. J. Mater. Sci.: Mater. Med. 2012, 23 (6), 1411-1420.

(22) Sirc, J., Kubinova, S.; Hobzova, R.; Stranska, D.; Kozlik, P.; Bosakova, Z.; Marekova, D.; Holan, V.; Sykova, E.; Michalek, J. Controlled Gentamicin Release from Multi-Layered Electrospun Nanofibrous Structures of Various Thicknesses. Int. J. Nanomed. 2012, 7, 53155325 .

(23) Dhand, C.; Venkatesh, M.; Barathi, V. A.; Harini, S.; Bairagi, S.; Goh T. L. E.; Muruganandham, N.; Low, K. Z. W.; Fazil, M. H. U. T.; Loh, X. J.; Srinivasan, D. K.; Liu, S. P.; Beuerman, R. W.; Verma, N. K.; Ramakrishna, S.; Lakshminarayanan, R. Bio-Inspired Crosslinking and Matrix-Drug Interactions for Advanced Wound Dressings with Long-Term Antimicrobial Activity. Biomaterials 2017, 138, 153-168.

(24) Angammana, C. J.; Jayaram, S. H. Analysis of the Effects of Solution Conductivity on Electrospinning Process and Fiber Morphology. IEEE Trans. Ind. Appl. 2011, 47 (3), 11091117.

(25) Rajzer, I.; Menaszek, E.; Kwiatkowski, R.; Planell, J. A.; Castano, O. Electrospun Gelatin/Poly(E-Caprolactone) Fibrous Scaffold Modified with Calcium Phosphate for Bone Tissue Engineering. Mater. Sci. Eng., C 2014, 44, 183-190.

(26) Rutkowska-Zbik, D.; Witko, M.; Fiedor, L. Ligation of Water to Magnesium Chelates of Biological Importance. J. Mol. Model. 2013, 19 (11), 4661-4667.

(27) Dhand, C.; Ong, S. T.; Dwivedi, N.; Diaz, S. M.; Venugopal, J. R.; Navaneethan, B.; Fazil, M. H. U. T.; Liu, S.; Seitz, V.; Wintermantel, E.; Beuerman, R. W.; Ramakrishna, S.; Verma, N. K.; Lakshminarayanan, R., Bio-Inspired In Situ Crosslinking and Mineralization of Electrospun Collagen Scaffolds for Bone Tissue Engineering. Biomaterials 2016, 104, 323-338. 
(28) GhavamiNejad, A.; Rajan Unnithan, A.; Ramachandra Kurup Sasikala, A.; Samarikhalaj, M.; Thomas, R. G.; Jeong, Y. Y.; Nasseri, S.; Murugesan, P.; Wu, D.; Hee Park, C.; Kim, C. S. Mussel-Inspired Electrospun Nanofibers Functionalized with SizeControlled Silver Nanoparticles for Wound Dressing Application. ACS Appl. Mater. Interfaces 2015, 7 (22), 12176-12183.

(29) Son Ho, Y.; Ryu Ji, H.; Lee, H.; Nam Yoon, S. Silver-Polydopamine Hybrid Coatings of Electrospun Poly(vinyl alcohol) Nanofibers. Macromol. Mater. Eng. 2013, 298 (5), 547-554.

(30) Son, H. Y.; Kim, I.; Nam, Y. S. On-Surface Synthesis of Metal Nanostructures on Solid and Hydrated Polymer Nanofibers Coated with Polydopamine. J. Ind. Eng. Chem. 2015, 30, 220-224.

(31) Dhand, C.; Barathi, V. A.; Ong, S. T.; Venkatesh, M.; Harini, S.; Dwivedi, N.; Goh, E. T. L.; Nandhakumar, M.; Venugopal, J. R.; Diaz, S. M.; Fazil, M. H. U. T.; Loh, X. J.; Ping, L. S.; Beuerman, R. W.; Verma, N. K.; Ramakrishna, S.; Lakshminarayanan, R. Latent Oxidative Polymerization of Catecholamines as Potential Cross-Linkers for Biocompatible and Multifunctional Biopolymer Scaffolds. ACS Appl. Mater. Interfaces 2016, 8 (47), 3226632281.

(32) Zangmeister, R. A.; Morris, T. A.; Tarlov, M. J. Characterization of Polydopamine Thin Films Deposited at Short Times by Autoxidation of Dopamine. Langmuir 2013, 29 (27), 8619-8628.

(33) He, S.; Zhou, P.; Wang, L.; Xiong, X.; Zhang, Y.; Deng, Y.; Wei, S. AntibioticDecorated Titanium with Enhanced Antibacterial Activity Through Adhesive Polydopamine for Dental/Bone Implant. J. R. Soc., Interface 2014, 11 (95), 20140169.

(34) Wu, H.; Ang, J. M.; Kong, J.; Zhao, C.; Du, Y.; Lu, X. One-Pot Synthesis of Polydopamine-Zn Complex Antifouling Coatings on Membranes for Ultrafiltration under Harsh Conditions. RSC Adv. 2016, 6 (105), 103390-103398.

(35) Ferraria, A. M.; Carapeto, A. P.; Botelho do Rego, A. M. X-ray Photoelectron Spectroscopy: Silver Salts Revisited. Vacuum 2012, 86 (12), 1988-1991. 
(36) S. Corneille, J.; He, J.-W.; Goodman, D. W. XPS Characterization of Ultra-Thin MgO Films on a Mo(100) Surface. Surf. Sci. 1994, 306 (3), p 269-278.

(37) Ingason, A. S.; Eriksson, A. K.; Lewin, E.; Jensen, J.; Olafsson, S. Growth and Structural Properties of Mg:C Thin Films Prepared by Magnetron Sputtering. Thin Solid Films 2010, 518 (15), 4225-4230.

(38) Wöll, C. The Chemistry and Physics of Zinc Oxide Surfaces. Prog. Surf. Sci. 2007, 82 (2), 55-120.

(39) Biesinger, M. C.; Lau, L. W. M.; Gerson, A. R.; Smart, R. S. C. Resolving Surface Chemical States in XPS Analysis of First Row Transition Metals, Oxides and Hydroxides: Sc, Ti, V, Cu and Zn. Appl. Surf. Sci. 2010, 257 (3), 887-898.

(40) Tanaka, Y.; Saito, H.; Tsutsumi, Y.; Doi, H.; Imai, H.; Hanawa, T. Active Hydroxyl Groups on Surface Oxide Film of Titanium, 316L Stainless Steel, and Cobalt-ChromiumMolybdenum Alloy and Its Effect on the Immobilization of Poly(Ethylene Glycol). Mater. Trans. 2008, 49 (4), 805-811.

(41) Demri, B.; Muster, D. XPS Study of Some Calcium Compounds. J. Mater. Process. Technol. 1995, 55 (3), 311-314.

(42) Blanchard, D. L.; Baer, D. R. The Interactions of Co, Mn and Water with Calcite Surfaces. Surf. Sci. 1992, 276 (1), 27-39.

(43) Gao, X.; Song, J.; Ji, P.; Zhang, X.; Li, X.; Xu, X.; Wang, M.; Zhang, S.; Deng, Y.; Deng, F.; Wei, S. Polydopamine-Templated Hydroxyapatite Reinforced Polycaprolactone Composite Nanofibers with Enhanced Cytocompatibility and Osteogenesis for Bone Tissue Engineering. ACS Appl. Mater. Interfaces 2016, 8 (5), 3499-3515.

(44) Luo, C.; Zou, Z.; Luo, B.; Wen, W.; Li, H.; Liu, M.; Zhou, C. Enhanced Mechanical Properties and Cytocompatibility of Electrospun Poly(L-Lactide) Composite Fiber Membranes Assisted by Polydopamine-Coated Halloysite Nanotubes. Appl. Surf. Sci. 2016, $369,82-91$. 
(45) Martins, A.; Pinho Elisabete, D.; Faria, S.; Pashkuleva, I.; Marques Alexandra, P.; Reis Rui, L.; Neves Nuno, M. Surface Modification of Electrospun Polycaprolactone Nanofiber Meshes by Plasma Treatment to Enhance Biological Performance. Small 2009, 5 (10), 11951206.

(46) Tanaka, K., Combination of Palladium(II) Ion with Gelatin. J. Photogr. Sci. 1973, 21 (3), 134-138.

(47) Yang, L.; Kong, J.; Zhou, D.; Ang Jia, M.; Phua Si, L.; Yee Wu, A.; Liu, H.; Huang, Y.; Lu, X. Transition-Metal-Ion-Mediated Polymerization of Dopamine: Mussel-Inspired Approach for the Facile Synthesis of Robust Transition-Metal Nanoparticle-Graphene Hybrids. Chem. - Eur. J. 2014, 20 (25), 7776-7783.

(48) Zanette, C.; Pelin, M.; Crosera, M.; Adami, G.; Bovenzi, M.; Larese, F. F.; Florio, C. Silver Nanoparticles Exert a Long-Lasting Antiproliferative Effect on Human Keratinocyte HaCat Cell Line. Toxicol. In Vitro. 2011, 25(5), 2053-2060.

(49) Boonkaew, B.; Kempf, M.; Kimble, R.; Cuttle, L. Cytotoxicity Testing of SilverContaining Burn Treatments using Primary and Immortal Skin Cells. Burns 2014, 40(8), 1562-1569.

(50) Burd, A.; Kwok Chi, H.; Hung Siu, C.; Chan Hui, S.; Gu, H.; Lam Wai, K.; Huang, L. A Comparative Study of the Cytotoxicity of Silver-Based Dressings in Monolayer Cell, Tissue Explant, and Animal Models. Wound Repair Regen. 2007, 15 (1), 94-104.

(51) Balne, P. K.; Harini, S.; Dhand, C.; Dwivedi, N.; Chalasani, M. L. S.; Verma, N. K.; Barathi, V. A.; Beuerman, R.; Agrawal, R.; Lakshminarayanan, R. Surface Characteristics and Antimicrobial Properties of Modified Catheter Surfaces by Polypyrogallol and Metal Ions. Mater. Sci. Eng., C 2018, 90, 673-684.

(52) Dhand, C.; Harini, S.; Venkatesh, M.; Dwivedi, N.; Ng, A.; Liu, S.; Verma, N. K.; Ramakrishna, S.; Beuerman, R. W.; Loh, X. J.; Lakshminarayanan, R. Multifunctional Polyphenols and Catecholamines Based Self-Defensive Films for Health Care Applications. ACS Appl. Mater. Interfaces 2016, 8 (2), 1220-1232. 
(53) Fullenkamp, D. E.; Rivera, J. G.; Gong, Y.-k.; Lau, K. H. A.; He, L.; Varshney, R.; Messersmith, P. B. Mussel-Inspired Silver-Releasing Antibacterial Hydrogels. Biomaterials 2012, 33 (15), 3783-3791.

(54) Yeroslavsky, G.; Richman, M.; Dawidowicz, L.-o.; Rahimipour, S. Sonochemically Produced Polydopamine Nanocapsules with Selective Antimicrobial Activity. Chem. Commun. 2013, 49 (51), 5721-5723.

(55) Wu, C.; Zhang, G.; Xia, T.; Li, Z.; Zhao, K.; Deng, Z.; Guo, D.; Peng, B. Bioinspired Synthesis of Polydopamine/Ag Nanocomposite Particles with Antibacterial Activities. Mater. Sci. Eng., C 2015, 55, 155-165.

(56) Paddle-Ledinek, J. E.; Nasa, Z.; Cleland, H. J. Effect of Different Wound Dressings on Cell Viability and Proliferation. Plast. Reconstr. Surg. 2006, 117 (7S), 110S-118S. 


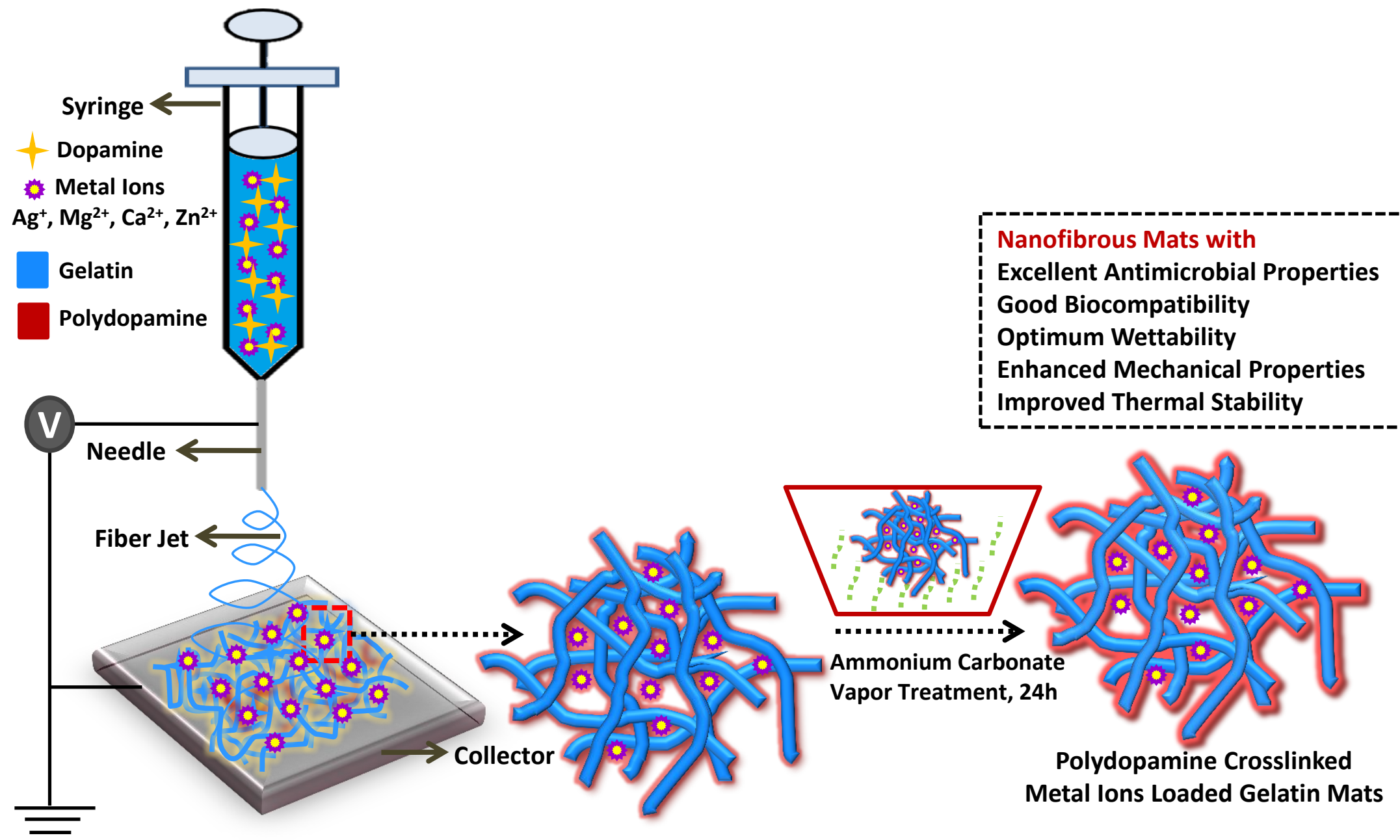

